\title{
BASES CONCEPTUALES PARA EL ESTUDIO INTERDISCIPLINARIO DEL SISTEMA JURÍDICO Y LAS FUTURAS GENERACIONES: PERSPECTIVA TEÓRICA Y EMPÍRICA DESDE EL DERECHO AMBIENTAL *
}

\author{
CONCEPTUAL BASES FOR THE INTERDISCIPLINARY STUDY OF \\ THE LEGAL SYSTEM AND THE FUTURE GENERATIONS: THEORETICAL \\ AND EMPIRICAL PERSPECTIVE FROM ENVIRONMENTAL LAW
}

\author{
Pierre Foy Valencia** \\ Pontificia Universidad Católica del Perú
}

\begin{abstract}
The main purpose of this article is to establish, in our medium the initiatory or preliminary bases for the interdisciplinary study of the Legal system in relation to future generations, applied conceptually and empirically to environmental law on an intergenerational perspective.
\end{abstract}

The author dives into the literature on the subject and draws the main lines of investigation on the subject, proposing several themes that compose the current debate on Earth's conservation by legal means.

KEY WORDS: Future Generations, Environment, Environmental Law, Common weal, Sustainability.
El presente artículo tiene como objetivo principal sentar en nuestro medio las bases iniciáticas o preliminares para el estudio interdisciplinario del Sistema Jurídico en relación con las futuras generaciones, aplicando conceptual y empíricamente al Derecho ambiental con una perspectiva intergeneracional.

El autor se adentra en la doctrina actual relevante y esboza las principales líneas de investigación del tópico, proponiendo al estudioso las diversas áreas que integran el actual debate respecto a las herramientas jurídicas que coadyuvarían a la conservación de la Tierra.

PALABRAS ClAVE: Futuras Generaciones, el Ambiente, Derecho Ambiental, Patrimonio Común, Sostenibilidad.

Artículo desarrollado en el marco de las tareas de investigación del Grupo de Investigación INTE-PUCP/Derecho Ambiental. Se contó con la opinión y colaboración de varios de los miembros de dicho grupo.

** Abogado. Máster en Derecho Ambiental por la Universidad del País Vasco. Magíster en Derecho Constitucional por la Pontificia Universidad Católica del Perú. (PUCP). Doctor en Derecho por la Universidad Alas Peruanas (UAP). Profesor Asociado en la Pontificia Universidad Católica del Perú (PUCP). Corresponsal peruano del Centre Internacional de Droit Comparé de I'Environment (CIDCE). Miembro de la Comisión de Derecho Ambiental de la Unión Internacional para la Conservación de la Naturaleza. Miembro del Consejo Consultivo de la Presidencia de la Corte Suprema, en la Comisión de Gestión Ambiental. Coordinador del Grupo de Investigación en Derecho Ambiental de la PUCP. Contacto: pfoy@pucp.edu.pe.

Nota del Editor: El presente artículo fue recibido por el Consejo Editorial de THËMIS-Revista de Derecho el 22 de junio de 2018 y aceptado por el mismo el 12 de febrero de 2019. 


\section{INTRODUCCIÓN}

Desde una perspectiva histórica y cultural, la preocupación acerca de las futuras generaciones (en adelante, "FG") se pierde en la noche de los tiempos (in ilo tempore) según la multivariedad de los patrones culturales y cosmovisiones de los pueblos. Se podría elaborar un estudio histórico antropológico sobre cómo se concibe el tiempo y la futuridad en las diversas culturas. La reputada especialista en la materia Edith Brown sostiene que:

Filósofos de diversas tradiciones culturales han reconocido que somos depositarios o administradores del medio ambiente. La tesis fundamental con respecto a las obligaciones que temo de conservar el planeta para las generaciones futuras y nuestros derechos de tener acceso a sus beneficios, se encuentra profundamente enraizada en la variada tradición jurídica de la comunidad internacional. Existen raíces en las tradiciones del common law y del derecho civil, en el derecho Islámico, en el derecho consuetudinario africano y en las tradiciones asiáticas ateas (1990, p. 52)

De otra parte, cabe recordar que las concepciones unilineales y las cíclicas sobre la historia, cada cual en sus propias posturas (Eliade, 1972), le signan un rol y un sentido a la futuridad del hombre y de sus sociedades. Un referente prototípico de esta perspectiva histórica la advertimos en el caso de Papúa Nueva Guinea. Si bien estamos frente a una expresión de modernidad que se expresa en el reconocimiento de la importancia de las FG en su Constitución Política, este se basa en una concepción tradicional de respeto por el legado transgeneracional ${ }^{1}$. En efecto, su Constitución de 1975 indica:

\section{National Goals and Directive Principles.}

\section{Natural resources and environment.}

We declare our fourth goal to be for Papua New Guinea's natural resources and environment to be conserved and used for the collective benefit of us all, and be replenished for the benefit of future generations.

We accordingly call for:

(1) wise use to be made of our natural resources and the environment in and on the land or seabed, in the sea, under the land, and in the air, in the interests of our development and in trust for future generations;

(2) the conservation and replenishment, for the benefit of ourselves and posterity, of the environment and its sacred, scenic, and historical qualities; and

(3) all necessary steps to be taken to give adequate protection to our valued birds, animals, fish, insects, plants and trees.

En tiempos relativamente más recientes, se advierte el rol pionero del oceanógrafo Jacques Cousteau en cuanto la reflexión ética y jurídica que representa el legado de las generaciones presentes a las generaciones futuras como se constata en su famoso documento "A Bill of Rights for Future Generations" (Ferrer Ortega, 2014, p. xxv), que fuera propuesto ante la ONU en el año 1994.

Sin embargo, esta preocupación moderna sobre las FG, acaso como consecuencia de los estragos y prospectivas a resultas de la Segunda Guerra Mundial, ya se advierte en la propia Carta de San Francisco de 1945, en la que se expresa que las naciones se comprometen "a preservar a las generaciones venideras del flagelo de la guerra que dos veces durante nuestra vida ha infligido a la Humanidad sufrimientos indecibles".

Posteriormente, se irá incorporando en diversos textos y compromisos internacionales, como la Convención de la Unesco para la Protección del Patrimonio Mundial, Cultural y Natural (World Heritage Convention, 1972)2. Destaca en 1987 el reconocido documento colectivo Nuestro Futuro Común o Informe Bruntland (Comisión Mundial del Medio Ambiente y del Desarrollo, Nuestro Futuro Común) con su célebre frase "27. Está en manos de la humanidad hacer que el desarrollo sea sostenible, duradero, a sea, asegurar que satisfaga las necesidades del presente sin comprometer la capacidad de las futuras generaciones para satisfacer las propias" que se reafirma en la reconocida Declaración de Río de 1992: "Principio 3: El derecho al desarrollo debe ejercerse en forma tal que responda equitativamente a las necesidades de desarrollo y ambientales de las generaciones presentes y futuras".

\footnotetext{
Esta concepción se advierte en The Papua New Guinea - Mama Graun Tribal Charter: For a Sustainable Future: "Los objetivos de la carta tribal de Mama Graun de PNG son: (i) fomentar el uso y la asignación de recursos naturales fuentes de una manera justa y amigable con el medio ambiente manera en beneficio del presente y el futuro generaciones; $[\ldots] "$.

2 La propia Declaración de Estocolmo sobre el Medio Humano (1972) alude a las generaciones presentes y futuras. Igualmente, los Convenios para la prevención de la contaminación marina provocada por el vertido desde buques y aeronaves (1972), sobre la prevención de la contaminación del mar por vertimiento de desechos y otras materias (1972), sobre el comercio internacional de especies amenazadas de la flora y fauna silvestres (1973) y las convenciones sobre mares regionales, como en el caso de la Convención de Barcelona sobre el mar mediterráneo (1976).
} 
Gráfico 1

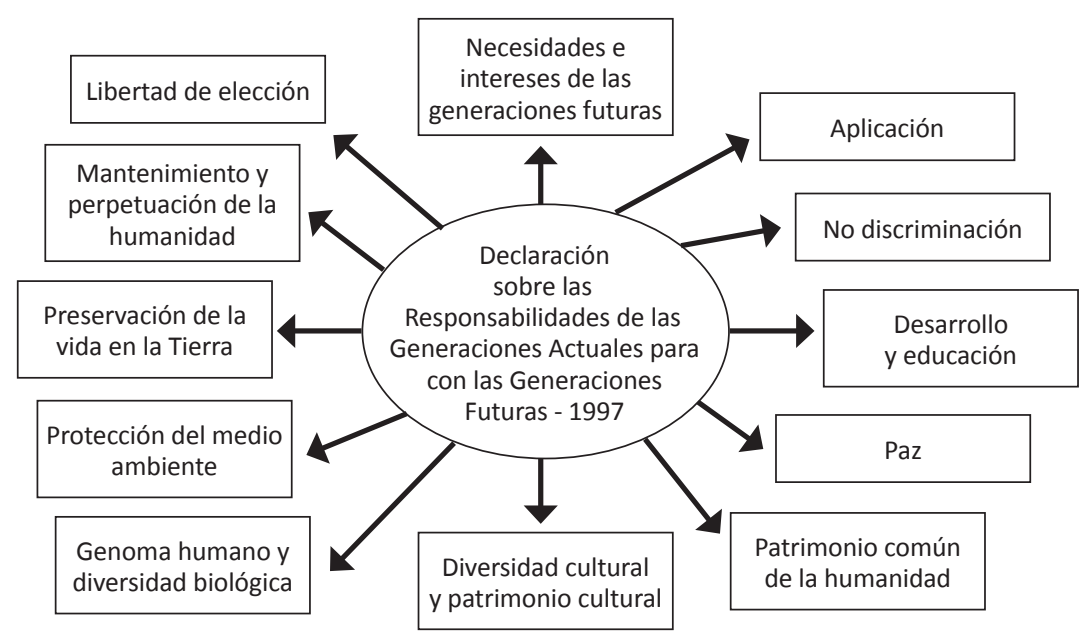

[Fuente: elaboración propia (Foy Valencia, 2016)]

Existe una percepción un tanto sesgada al circunscribir la cuestión de las FG a los temas de la niñez/infancia, el medio ambiente o el patrimonio cultural, puesto que el escenario es mucho más amplio. En efecto, si analizamos la Declaración sobre las Responsabilidades de las Generaciones Actuales para con las Generaciones Futuras de 1997, podremos identificar una diversidad temática que aborda muchos más puntos de lo que hemos indicado, tales como el del genoma humano, la no discriminación o la paz como se colige en el gráfico 1.

Por cierto, y sin estar finalmente ante un instrumento jurídico, la propuesta de Cousteau, A Bill of Rights for Future Generations, proclamaba la necesidad de asegurar el reconocimiento universal del derecho que le asiste a las generaciones futuras de gozar de la vida en la tierra como fundamento de la historia humana, de la cultura y de los vínculos sociales que hacen de cada generación e individuo un miembro de una misma familia humana. Ello conlleva a la responsabilidad y deber fiduciario de cada generación para devolver el patrimonio que ha recibido de la tierra en iguales o mejores condiciones. Tesis afirmada por Edith Brown Weiss, en el sentido de que "cada generación recibe un legado natural y cultural como fideicomiso de las generaciones anteriores, para que a su vez sea transmitido a las generaciones futuras" (1999, p. 39) ${ }^{3}$.

\section{MARCO METODOLÓGICO PARA EL ESTUDIO INTERDISCIPLINARIO DEL SISTEMA JURÍDI- CO EN RELACIÓN CON LAS FG}

Partimos para este análisis de la comúnmente llamada concepción interdisciplinaria del sistema jurídico, a pesar de que el término más adecuado es el de la transdisciplinariedad. En ese sentido, traemos a colación una premisa de "La investigación en el Derecho ambiental. Hacia una metodología de la investigación para la disertación jurídica ambiental" en la que se afirma:

El saber transdisciplinario como redescubrimiento del saber integrativo posmoderno, provee conceptos y métodos para una nueva postura y acción del quehacer humano y por ende del saber y quehacer jurídico, en particular del sistema jurídico ambiental. La transdisciplinariedad conforma un referente central que alimenta las fuentes materiales del Derecho ambiental. Sin embargo, al menos por ahora y por aproximación, se viene internalizando el discurso o término de la interdisciplinariedad (Foy, de próxima publicación).

A mayor abundamiento, si nos atenemos a los postulados de la Carta de la Transdisciplinariedad ${ }^{4}$, advertiremos las limitaciones e insuficiencias de pretender envolver o reducir al ser humano y sus saberes en estructuras formales o a un solo nivel de realidad cuando la visión transdisciplinaria es

4 Ver documento "La Transdisciplinariedad - Manifiesto" elaborado por Basarab Nicolescu (1996) que contiene la difundida Carta de la Transdisciplinariedad, fruto del Primer Congreso Mundial de Transdisciplinariedad. Convento de Arrábida, en Portugal del 2 al 7 de noviembre de 1994. 
más compleja y contiene a su vez diversos saberes disciplinarios que los integra y articula a un nivel más amplio y cualitativo. ${ }^{5}$

Para una operatividad jurídica en relación con este enfoque transdisciplinario (en adelante nos atendremos al término interdisciplinario), debemos considerar que esta concepción ciertamente expande su horizonte más allá de las denominadas ciencias sociales; máxime en la perspectiva ambiental que abordaremos y, en consecuencia, reafirmamos la siguiente premisa:

El insurgente enfoque socio jurídico sobre todo de carácter empirista, emergió a modo de superación de las limitaciones de los enfoques dogmáticos e iusnaturalistas, sin llegar a representar per se el culmen del conocimiento o saber jurídico. No obstante, ofrece una valiosa mirada y llamada de atención importante ante el imperativo de contextualizar los fenómenos jurídicos. (...) El tránsito o si se quiere la amplitud, hacia los enfoques más integrativos, sin sesgos sociologizantes, como es el caso de los sistémicos e interdisciplinarios, expresan una dimensión más compleja, que igualmente deben abordarse con mesura y sin idealismos o fundamentalismos holísticos [...] (Foy, de próxima publicación).

\section{LAS FUTURAS GENERACIONES (FG) COMO OBJETO Y “REALIDAD” (TRANS)INTERDISCI- PLINARIA: A MODO DE FUENTES MATERIA- LES EXTRAJURÍDICAS DEL DERECHO Y LAS FUTURAS GENERACIONES}

Resulta interesante una de las conclusiones de Diotallevi, al sostener que:

[L]os sujetos que comparten un escenario temporal, una generación, y que no pareciera compartir ninguna convergencia de vida o valores, innegablemente no pueden estar de acuerdo en el hecho de verse obligados a convivir. La condición de facto de la coexistencia de generaciones $u$ hombres diferentes dentro del espacio "Generaciones" debe necesariamente dar lugar a nuevas formas de coexistencia, no basadas en la búsqueda de una base común o un origen común, sino en un destino común (2013, p. 440) [traducción libre].

En efecto, en esta reflexión identificamos un núcleo esencial de la cuestión sobre las FG que se reiterará a lo largo de toda la literatura especializada sobre la materia; esto es cómo articular o ubicar un punto fiel que considere las legítimas aspiraciones de las actuales generaciones con las necesidades de las FG. Surgen múltiples interrogantes -que a su vez requerirán sus respectivas traducciones jurídicas- como, por ejemplo, cómo entender la legitimidad de ambas posturas, cuáles deberían ser los mecanismos para garantizar una "economía y una contabilidad de lo intergeneracional", el cuánto y el cómo de la provisión hacia lo intergeneracional, etc.

Estamos ante la discusión sostenida por Tremmel: ¿Qué mantener como objetivo axiológico? ¿Capital ${ }^{6}$ o bienestar ${ }^{7}$ ? o, en todo caso, ¿cómo equilibrarlos? (2009, p. 70). A ello se suma lo innecesario e inviable de un discurso de reciprocidad contractual cuando la previsión y prevención intergeneracional también atañe al tiempo generacional vigente como lo sostienen Hoecke y Ost en su estudio "Del contrato a la transmisión. Sobre la responsabilidad hacia las generaciones futuras" (1990, p. 630). Asimismo, se integran las temáticas relacionadas a las externalidades generacionales, los problemas de cálculo, la necesidad del descuento intergeneracional o el reparto intergeneracional de los derechos de propiedad sobre el medio ambiente, como lo plantean Pasqual y Rocaber, y Souto Nieves (2003).

En líneas anteriores, hemos indicado un tanto los orígenes relativamente modernos de la preocupación por las $\mathrm{FG}^{8}$, a pesar de que esta se encuadra en una perspectiva cultural y diacrónica de muy

5 Hay quienes cuestionan estos enfoques, hasta lo tildan de oscurantistas y confusos, como "expresión de un puro deseo mítico, oscuro y confuso" propio de una pretendida e inviable unificación de las ciencias. David Alvargonzález Rodríguez (Universidad de Oviedo) "La transdisciplinariedad como mito milenarista". Recuperado de: http://www.encuentros-multidisciplinares.org/Revistan\%C2\%BA34/David\%20Alvargonz\%C3\%A1lez\%20Rodr\%C3\%ADguez.pdf.

6 El capital natural, social y cultural no es comercializable, refiere Tremmel, por oposición al enfoque tradicional o más convencional del capital

7 El bienestar está asociado a: Felicidad, Satisfacción, Placer, Utilidad, Calidad de vida y existen diversos índices de medición del bienestar, ya sean subjetivos, como objetivos. En este último caso se suelen aplicar: Índice de Desarrollo Humano (en adelante, "IDH"), de bienestar humano (en adelante, "HWI"), ponderado de progreso social (en adelante, "WISP").

8 En perspectiva jurídica internacional Saruwatari Zavala ha rastreado el origen, seguimiento y profundización del concepto de generaciones futuras en el derecho internacional de los derechos humanos, acotando que "Aunque la conceptualización de este nuevo sujeto empezó en los instrumentos internacionales, es de reconocerse que paulatinamente se ha ido concretando en legislaciones nacionales" (2009, p. 29). 


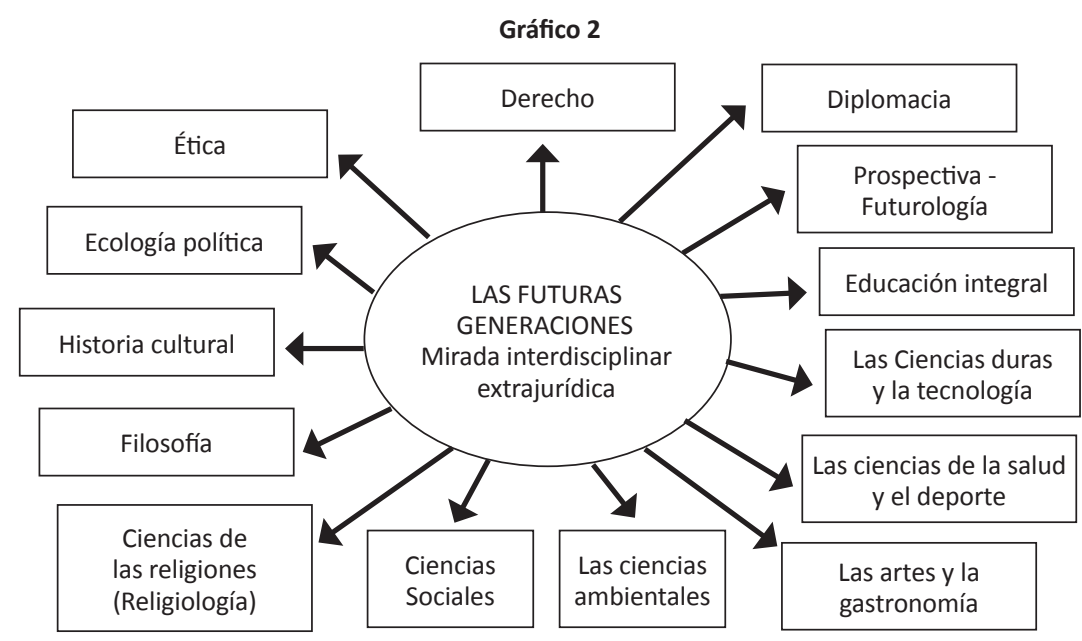

[Fuente: elaboración propia (Foy Valencia, 2016)]

larga duración. En buena cuenta podemos desde ya afirmar -como lo hemos venido sugiriendoque la preocupación acerca de las FG tiene una dimensión interdisciplinaria pluritemática que va más allá de los jurídico tal como nos lo revela el cuadro que hemos elaborado, con un listado enumerativo de enfoques disciplinarios - no sólo jurídicos ni mucho menos- que convergen y se integran a la preocupación intergeneracional. Ver gráfico 2 .

Veamos enumerativamente algunos ejemplos más específicos:

\section{A. Historia Cultural}

Se pueden rastrear las raíces de las FG en "las tradiciones del common law y del derecho civil, en el derecho islámico, en el derecho consuetudinario africano y en las tradiciones asiáticas ateas" (Brown Weiss, 1990, p. 52), que a su vez se sostienen en profundas raíces histórico-culturales.

\section{B. Ética}

En la ética de la sustentabilidad de políticas de desarrollo, R. Guimaraes -aunque no participamos propiamente de su pensamiento sociopolíticoaboga por la necesidad de lo siguiente:

Un nuevo paradigma de desarrollo, que coloque al ser humano en el centro del proceso de desarrollo, que considere el crecimiento económico como un medio y no como un fin (...) Las nuevas bases de convivencia que proveen de gobernabilidad al sistema político requieren por tanto de que proteja las oportunidades de vida de las generaciones actuales y futuras y que, por ende, respete la integridad de los sistemas naturales que permiten la existencia de vida en el planeta (2002, p. 59).

Esta dimensión ética ya la había anunciado el filósofo Jonás (1966) a partir de su preocupación sobre la amenaza tecnológica y el límite ético por el respeto a la vida, las relaciones hombre-entorno, la supervivencia de la especie humana y, por ende, la responsabilidad moral de las actuales generaciones respecto de las sobrevivientes (De Siqueira, 2001).

\section{Filosofía}

Si nos atenemos al principio de autoridad académica, en realidad todo el Handbook of Intergenerational Justice (Tremmel, 2006) se encuentra revestido de una dimensión filosófica tanto por la pertenencia de sus autores (Tremmel, Gosseries o Lumer) como por los enfoques y contenidos. Ciertamente y al alimón, el estudio de obras como "Principios de justicia generacional", de Christoph Lumer; "Cambio de reglas y justicia intergeneracional", de Axel Gosseries y Mathias Hungerbühler; o "Protegiendo a las futuras generaciones: traspaso intergeneracional de responsabilidades, ineptitud teórica y un resumen para un principio precautorio nuclear de alcance global", de Stephen M. Gardiner, tiene una profunda fundamentación y perspectiva filosófica.

Desde nuestra región no deja de ser aleccionadora la reflexión de los hermanos Ferrer Ortega en cuanto en su artículo "El problema de la fundamentación filosófica de los derechos de las generaciones futuras" (2008) se señala que ${ }^{9}$

9 A mayor abundamiento estos autores proponen conceptos fundamentales de una reflexión filosófica sobre los derechos de futuras generaciones: 1) Posibilidad de una "futurología" y una "ciencia de los efectos lejanos de la acción técnica" 
[...] 3) La historia nos muestra que hemos adquirido derechos gracias al esfuerzo de generaciones pasadas (por ejemplo, gracias a la Revolución francesa, o gracias a activistas como Martin Luther King). Asimismo, hemos perdido derechos o nuestros derechos han sido violentados por obra de generaciones anteriores. Con base en la conciencia de nuestra historicidad, ¿no cabe introducir categorías como "gratitud histórica" o "errores históricos" como criterios de legislación sobre derechos de generaciones futuras? No podemos -como observamos antes- reclamar a las generaciones anteriores, pero bien podemos no incurrir en los mismos errores, así como extender el legado que hemos recibido en la medida en que éste es valioso.

\section{Ecología política}

Por ejemplo, el texto de Joshua Beneite "En diálogo con el futuro: Ecología política y justicia intergeneracional" postula que desde y bajo el amparo de determinadas premisas de la ecología política debemos identificar aquellos recursos sociales, así como las instituciones anticipativas e ideales de futuro, y empezar a construir y configurar nuestro futuro ideal para el mundo actual y todas sus futuras generaciones (2014, p. 26).

La ciencia de la ecología política en una concepción prospectiva sobre lo intergeneracional ofrece un escenario muy rico de reflexión y proposición, siempre que no arriba a plataformas escatológicas o de ideología pretendidamente salvíficas.

\section{E. Religiología}

Las religiones según sus diversas cosmovisiones y discursos confesionales insertan la dimensión intergeneracional. Por ejemplo, en la tradición judeocristiana, Dios le entrega al pueblo y a su descendencia la tierra como una posesión perpetua (Génesis, 17:38) y algo similar acontece con los mandatos islámicos (Sikandar, 2002).

\section{F. Prospectiva y futurología}

Según Armas y Anicama, “(...) la prospectiva involucra una nueva necesidad de las administraciones, sean estas públicas o privadas, para preparar con eficiencia y eficacia los planeamientos estratégicos institucionales, ante un mundo tan complejo y con predominio de la incertidumbre". En ese sentido, es importante interrelacionar esta dimensión futurológica respecto de los problemas globales actuales y las implicancias y alertas que recibirán sobre las FG (2015, p. 7).

En realidad, futurología y FG son aspectos inescindibles e intercambiables: no es concebible una reflexión futurológica sin tomar en cuenta los denominados "intereses de las futuras generaciones".

\section{G. Ciencia política}

De los diversos escenarios politológicos, nos referiremos al campo de las políticas públicas y las FG. En esa perspectiva, Göpel y Pearce -cuando en el marco de la Fundación World Future Council, se plantean "Cómo incluir a las generaciones futuras en la elaboración de políticas" (2004)- consideran que "[l]a formulación de políticas parece haberse quedado estancada en una forma de pensar inadecuada ante los graves retos mundiales. Tenemos la responsabilidad colectiva de aplicar y proporcionar ambiciosas estrategias para el desarrollo sostenible en un mundo interconectado de 9,6 millones de personas que habrá en el año 2050".

Precisamente, esto nos recuerda al Informe Bruntland cuando en el año 1987 recusa la paradoja de la condición interdependiente e integrada de los desafíos actuales frente a las formas de concebir nuestra institución que se configuran de manera independientes, fragmentadas y "que operan con mandatos relativamente limitados con procesos de toma de decisiones cerrados" a diferencia de los sistemas ecológicos en el mundo real.

\section{H. Ciencias ambientales}

Las ciencias ambientales permiten contribuir a una sostenibilidad intergeneracional: si se considera que la "conciencia colectiva en torno a la importancia de un desarrollo armónico entre ciencia, tecnología, educación y oferta ambiental, como para que el crecimiento económico pudiera ser sostenible en el largo plazo" (Panario y Gutiérrez, 2005), entonces estamos ante una visión que integra las ciencias ambientales en una perspectiva de los intereses intergeneracionales.

\section{Temáticas del sistema jurídico y las futuras generaciones}

Son muchas las temáticas que se han ido derivando y construyendo en materia de FG en su correlación con los sistemas jurídicos. De suyo, se ha venido instaurando una nueva rama aún discutible

como fundamento de la responsabilidad por futuras generaciones. 2) "Heurística del temor" (Hans Jonás). 3) "Ética del género humano". 4) "Justicia entre generaciones". 
y debatible conocida como Derecho de la Futuras Generaciones que, de alguna manera, busca responder a la incógnita de cómo los sistemas jurídicos vienen insertando y transversalizando la dimensión de los intergeneracional, valiéndose para ello de las ramas, conceptos e instituciones jurídicas preexistentes. Por ejemplo, el jurista alemán Peter Häberle (2009) postula inclusive un Derecho constitucional para las futuras generaciones o Derecho constitucional generacional a partir de la concepción de un contrato social generacional que supone otros criterios como el de no reciprocidad, pues como sostienen Ost y van Hoecke:

[...] un ser humano no puede ser apartado de la cadena de generaciones sucesivas. Para tomar esto en cuenta, tenemos que partir de conceptos como "responsabilidad" y traspaso de "herencia" y de principios como la "igualdad entre generaciones" y no de conceptos como "contrato" y "reciprocidad". El hecho de que somos lo que somos gracias a las generaciones previas, crea el deber de transferir unas condiciones similares para una buena vida a las generaciones futuras. Desde este punto de vista, todas las generaciones son iguales, sin ninguna reciprocidad (1999, p. 627).

A continuación, abordaremos algunos de los aspectos de esta naciente disciplina (ius novo).

\section{DERECHOS DE LAS FUTURAS GENERACIO- NES Y DERECHO CONSTITUCIONAL PARA LAS FUTURAS GENERACIONES}

Tal como habíamos indicado, el célebre jurista alemán Peter Häberle (2009) alude a un derecho constitucional para las futuras generaciones como "la otra forma del contrato social: el contrato generacional", procurando buscar un punto de equilibrio entre la libertad de la generación actual y las obligaciones concernientes a los intereses de futuras generaciones. Esto nos evoca al filósofo Michel Serres, quien en "El Contrato Natural" (1991) pro- pone ampliar el viejo contrato social, extendiéndolo al mundo natural, a la Tierra. Häberle considera que el problema generacional debería ser considerado i) como uno de los lineamientos de la constitución y ii) como un orden legal básico del estado y la sociedad.

Tal como hemos señalado en otra oportunidad (Foy Valencia, 2016, p. 3):

Las experiencias europeas tienden a afirmar este nuevo derecho intergeneracional, por ejemplo, cuando se plantea una suerte de extensivo gasto territorial, que implicaría un contrato generacional mundial que uniría a todos los pueblos y ciudadanos de nuestro planeta azul (Häberle, 2009).

No obstante estas miradas europeo-céntricas o eurogénicas, no cabe desestimar otros enfoques constitucionales; por ejemplo, el reivindicado por el fallecido iusambientalista colombiano José María Borrero en su libro "Los Derechos Ambientales. Una visión desde el sur" en donde, al estudiar la estructura del Constitucionalismo Ambiental Asiático-Oceánico, se indican algunas características tales como el de la "Equidad Intergeneracional", en ese entonces expresada sobre todo por Irán y, en particular, por Papúa Nueva Guinea: como es el caso del Preámbulo de la Carta Política de dicho estado en que dejaba entrever el reconocimiento del crédito planetario como fundamento de la justicia entre generaciones para garantizar el respectivo uso de la oferta ambiental biosférica de parte de las generaciones venideras.

Como una expresión de contenidos jurídicos temáticos de la justicia intergeneracional, que se entiende como uno de los ejes del derecho intergeneracional, mostramos los alcances del citado Handbook of Intergenerational Justice (Tremmel, 2006):

\begin{tabular}{|l|l|}
\hline \multicolumn{2}{|c|}{ PARTE I I FUNDAMENTOS Y DEFINICIONES DE JUSTICIA GENERACIONAL } \\
\hline 1. Responsabilidad para las generaciones futuras: alcance y límites & Dieter Birnbacher \\
\hline 2. Principios de justicia generacional & Christoph Lumer \\
\hline 3. La imposibilidad de una teoría de la justicia intergeneracional & Wilfred Beckerman \\
\hline 4. John Rawls sobre los derechos de las generaciones futuras & Claus Dierksmeier \\
\hline 5. Justicia entre generaciones: los límites de la justicia procesal & Michael Wallack \\
\hline 6. Cambio de reglas y justicia intergeneracional & Axel Gosseries y Mathias Hungerbühler \\
\hline $\begin{array}{l}\text { 7. El Indicador de Sostenibilidad Económica } \\
\text { 8. Proteger a las generaciones futuras: intergeneracional avalancha, inepti- } \\
\text { tud teórica y un resumen para un principio de precaución central global }\end{array}$ & Stephen M. Gardiner \\
\hline $\begin{array}{l}\text { 9. Determinantes institucionales de la deuda pública: una política perspec- } \\
\text { tiva económica }\end{array}$ & Bernd Süssmuth y Robert K. Von Weizsäcker \\
\hline
\end{tabular}




\begin{tabular}{|l|l|}
\hline \multicolumn{2}{|c|}{ PARTE II I INSTITUCIONALIZACIÓN DE JUSTICIA GENERACIONAL } \\
\hline $\begin{array}{l}\text { 10. Establecimiento de la justicia intergeneracional en las constituciones } \\
\text { nacionales }\end{array}$ & Joerg Chet Tremmel \\
\hline $\begin{array}{l}\text { 11. Una ley constitucional para las generaciones futuras: la 'otra' forma del } \\
\text { contrato social: el contrato de generación }\end{array}$ & Peter Häberle \\
\hline $\begin{array}{l}\text { 12. La Carta Constitucional francesa para el medio ambiente: ¿̇un instru- } \\
\text { mento efectivo? }\end{array}$ & Dominique Bourg \\
\hline $\begin{array}{l}\text { 13. Comisión para las generaciones futuras en la Knéset: lecciones apren- } \\
\text { didas }\end{array}$ & Shlomo Shoham y Nira Lamay \\
\hline $\begin{array}{l}\text { 14. Protección institucional de las generaciones venideras - Defensor del } \\
\text { Pueblo para las Generaciones Futuras en Hungría }\end{array}$ & Benedek Jávor \\
\hline 15. El papel de CPB en la política económica holandesa & Rocus van Opstal y Jacqueline Timmerhuis \\
\hline 16. Justicia intergeneracional & Emmanuel Agius \\
\hline
\end{tabular}

[Listado tomado del citado libro - elaboración propia]

Para finalizar, como señala Häberle "las demandas globales para la protección del medioambiente, la naturaleza y la cultura y las varias legislaciones interestatales apuntan en esa dirección. Esto también aclararía la conexión intertemporal entre las generaciones humanas. Y así, la intención de "ciudadanía mundial" de Kant ganaría la dimensión de profundidad en el tiempo, en paralelo a la de espacio" (2009, p. 35).

\section{A. Justicia intergeneracional}

Pese a la posición de Wilfred Beckerman, que se decanta por la imposibilidad de una teoría de la justicia intergeneracional (Tremmel, p. 206), este enfoque ha ido ganando terreno y consistencia epistemológica. Tan es así que en la actualidad se cuenta con la publicación Intergenerational Justice Review, en uno de cuyos números (número 10) se afirma que la: "[Justicia intergeneracional] significa que el potencial de los niños y las futuras generaciones para satisfacer sus necesidades y cumplir sus aspiraciones debe ser, al menos, tan grande como el que pueden esgrimir las generaciones hoy".

Uno de los pensadores más reconocidos en la materia, Axel Gosseries (2014, 2017), ha desarrollado una sinopsis acerca de las diversas teorías de la justicia intergeneracional, teniendo en cuenta dos dimensiones (ahorro/desahorro) y tres modalidades (prohibición, autorización y obligación). En realidad, tales teorías facilitan recursos interpretativos para comprender esta justica a partir de lógicas diversas que pueden conducir a resultados muy variados y complejos (Gosseries, 2014, p. 234). Este mismo autor, junto con Meyer en "Intergenerational Justice", sostiene que, si desde ya por lo general resulta complicado reconocer la responsa- bilidad moral en situaciones conflictivas, cuando se trata de las responsabilidades hacia las futuras generaciones esto abre una brecha mayor, puesto que no se puede pronosticar la incertidumbre. Es decir, hay que afrontar el anonimato de los "pacientes morales" o también la falta de reciprocidad en el tiempo y distancia (Gosseries y Meyer, 2009).

La justicia intergeneracional se sostiene en el principio de equidad o igualdad de derecho de los diversos agentes y colectivos generacionales. Por eso, C. J. George, coordinador regional para Asia Meridional de Terre des hommes (Alemania), integra dentro del enfoque de la justicia intergeneracional conceptos tales como "el desarrollo sustentable, justicia social, derechos de niños y jóvenes, calentamiento global y cambio climático" $(2012)^{10}$.

\section{B. Interés intergeneracional y comunidad moral}

Sobre esta materia espinosa, Joshua Beneite Martí en sus "Propuestas para una justicia intergeneracional 'omnicomprensiva'” señala que es válido objetar, o si se quiere, afirmar que no necesariamente puedan coincidir los intereses actuales con los de las generaciones futuras humanas, inclusive de las generaciones futuras no humanas -a pesar de no precisar este alcance, pareciera referirse a otras vidas como en el caso de los animales. Sin embargo, una justicia intergeneracional omnicomprensiva debe ser capaz de incluir a la vida del presente y del futuro, no obstante que la pretensión de buscar la representación de los "intereses de dos entidades 'mudas', como las generaciones futuras humanas y la naturaleza no humana, da lugar a muchas especulaciones" y desafíos para el sistema jurídico (añadimos).

10 Es el concepto de equidad o igualdad de derechos entre generaciones de niños, jóvenes, adultos y sobrevivientes y también entre generaciones presentes, pasadas y futuras". 
En este contexto, Riechmann Fernández considera que los dos únicos prerrequisitos lógicos necesarios para que algo pueda ser representado son:

\section{a) que A tenga intereses, $y$}

b) que el representante o bien conozca los intereses de $A$ por habérselos comunicado el propio $A$, o bien sepa lo suficiente sobre los intereses de A como para hacer juicios razonablemente fundados (no aleatorios) sobre cómo afectarían a los intereses de A los diferentes cursos de acción.Ambos prerrequisitos se cumplirían en el caso de los animales no humanos y de las generaciones futuras (2003, p. 190).

La mencionada Declaración sobre las Responsabilidades de las Generaciones Actuales para con las Generaciones Futuras (1997) afirma esta concepción en su "Artículo 1 Necesidades e intereses de las generaciones futuras. Las generaciones actua- les tienen la responsabilidad de garantizar la plena salvaguardia de las necesidades y los intereses de las generaciones presentes y futuras".

En cuanto a la comunidad moral, o mejor dicho a la ampliación de los límites de la comunidad moral, según Garrido Peña, para la ética ecológica dicha ampliación se extiende a las generaciones futuras y a toda la comunidad biótica bajo la ecuación "comunidad moral = comunidad biótica intertemporal" (2011, p. 13).

Pese a que la representación de dicha comunidad se torna borrosa o difusa, puesto que tendrá grados diferentes, escalonados, de pertenencia al mismo, todos tendrían un "estatus de valor en sí moral que genera obligaciones morales de protección, y limita el libre uso y disposición, por parte de los agentes morales". Por ello Garrido Peña (2011, p. 16) identifica tres tipos de miembros que pertenecen a la de la comunidad moral:

\begin{tabular}{|c|l|}
\hline $\begin{array}{c}\text { Tipos de miembros de } \\
\text { la comunidad moral }\end{array}$ & \multicolumn{1}{c|}{ Conceptualización } \\
\hline Los agentes morales & $\begin{array}{l}\text { "Son los miembros de la especie humana que tiene derechos y obligaciones, pues el ejercicio de } \\
\text { sus derechos puede racional e intencionalmente provocar daño en los derechos de los demás } \\
\text { miembros de la comunidad. El agente moral requiere de la autolimitación racional y reflexiva de la } \\
\text { autonomía para hacer posible la cooperación interespecífica". }\end{array}$ \\
\hline Los sujetos morales & $\begin{array}{l}\text { "son los animales, especialmente los vertebrados. Son sujetos porque tienen derechos (son bienes } \\
\text { valiosos y protegibles en sí mismos) pero no obligaciones, pues su conducta no puede generar } \\
\text { daño por medio de acciones intencionales reflexivas. La obligación que fuerza la protección de sus } \\
\text { derechos es la de conservar su existencia (colectiva e individual) y a no ser sometido arbitraria e } \\
\text { injustificadamente a daño, sufrimiento o desaparición" }\end{array}$ \\
\hline Objeto moral & $\begin{array}{l}\text { "Éste no goza de derechos (no es un bien valioso en sí mismo en toda la escala, desde el individuo } \\
\text { a la especie) sino que son sólo ecológicamente valiosos. Esto implica que las obligaciones de pro- } \\
\text { tección que genera están en base a la utilidad ecológica del mismo. Ejemplo de este tipo de objetos } \\
\text { morales son la comunidad botánica y forestal, los hongos, los microorganismos (bacterias y virus), } \\
\text { los ecosistemas, el agua, los suelos y la totalidad de geomateriales"11 }\end{array}$ \\
\hline
\end{tabular}

En cuanto a la personalidad jurídica de las FG, en la experiencia colombiana se ha sostenido que esta debe estar "acorde con la realidad social, cultural y ecológica de la especie humana y el resto de seres vivos. Se debe reconocer como sujeto de derechos a las generaciones futuras entendidas como los probables seres humanos que nacerán después de nosotros en un tiempo indefinido hacia el futuro". En ese sentido, plantean que el concepto de personalidad jurídica debe ser ampliado en el Código Civil, incorporando lo siguiente: "La personalidad jurídica se adquiere al nacer vivo $y$ estar completamente separado del vientre materno, igualmente se reconoce personalidad jurídica a las GF, entendidas estas como la continuación de la especie humana en el futuro" (López, 2014; Santacoloma, 2014).

El interesante estudio de Bradford Mank, Standing and Future Generations: Does Massachusetts v. EPA Open Standing for Generations to Come? refiere que una buena razón para preguntarse acerca de la importancia para ver si alguien tiene legitimación para demandar en nombre de las generaciones futuras en los tribunales federales es que las generaciones futuras no pueden votar, por lo que los jueces federales no electos serían más adecuados para proteger sus intereses antes que los políticos (presentistas, añadimos) (2009, p. 4).

11 "Que no tengan derechos no significa que no se les aplique el principio de mínima lesividad (no dañar sin motivo razonable alguno) o de maximización de la biodiversidad (cuanta más diversidad mejor) sino que en la protección de estos objetos priman: la conservación con respecto al bienestar, la especie con respecto al individuo y la ecológica sobre cualquier otra". (Garrido Peña, 2011, p. 16). 
Sin duda estamos ante un escenario polémico y debatible con implicancias ético-filosóficas y jurídicas, además de otras dimensiones (tecnoeconómicas, contables, entre otras).

\section{Representación de las futuras generacio- nes: Ombudsman o defensor de las FG}

En otro lugar hemos resaltado la calidad de idea germinante y de progresiva implementación que tiene la creación de una entidad u organismo ombudsman, tutor, guardián, comisario, entre otras análogas (Foy Valencia, 2015, p. 10). Inclusive desde la perspectiva de la democracia política se cuestiona el "presentismo político" en el sentido de que las democracias son propensas a un sesgo en las leyes a favor del presente (presentismo) por encima o sobrepasando la necesidad de las FG (Thompson, 2010). En este contexto, se ha planteado que las generaciones actuales pueden representar a las generaciones futuras actuando como fideicomisarios de la democracia. El principio general sería que las generaciones presentes deben actuar para proteger el proceso democrático de su tiempo, procurando asegurarse de que los futuros ciudadanos continúen teniendo un control competente sobre su toma de decisiones colectivas (Thompson, 2010).

Existen diversas experiencias orientadas a institucionalizar políticamente estas apuestas por las FG como se advierte en muchas situaciones comparadas. Mencionamos al alimón algunas de ellas: Comisario para un Futuro Sostenible (en el Principado de Gales), comisario parlamentario del Medioambiente (como es en Nueva Zelanda, donde se le conoce como el guardián de la Perspectiva a Largo Plazo), comisión nacional para Generaciones Futuras (Israel) ${ }^{12}$, comisario de los derechos fundamentales, responsable de la Protección de los Intereses de las Generaciones Futuras (Hungría), entre otras.
Sobre las instituciones de protección y vigilancia de las FG, se han entretejido muchas alternativas y modelos, como el de una "oficina de un guardián para las futuras generaciones", propuesta presentada por Malta en la cuarta sesión del Grupo de Trabajo III del Comité Preparatorio de la CNUMAD, llevada a cabo en 1991 en Nueva York.

Refiere Ferre (2014, pp. 297-298) que, de las diversas experiencias propuestas en torno a este tema, el diplomático hindú Malhotra desprendió cinco preguntas abiertas:

a) ¿El mandato del guardián de las futuras generaciones se limitará a cuestiones ambientales ignorando otras áreas en las que aquellas podrían tener intereses?

b) ¿Generaciones de otros seres distintos a los humanos deberían ser considerados?

c) ¿Hasta dónde pueden ser medidos los intereses, opciones y gustos de las generaciones futuras tomando en cuenta el cambio de las capacidades tecnológicas presentes transformaciones, que incluso pueden producirse de una acelerada?

d) ¿A qué generación dará preferencia el guardián en caso de conflicto entre futuras generaciones distintas?

e) Tomando en consideración la incertidumbre hacia el futuro, ¿puede asumirse que el objetivo de un hipotético guardián será invariablemente superior al de otros?

Del documento "¿Cómo incluir a las generaciones futuras en la elaboración de políticas?" en Future Justice, hemos elaborado el siguiente esquema que consagra criterios con los que debe trabajar un tutor o defensor de las FG. Ver gráfico 3.

Gráfico 3

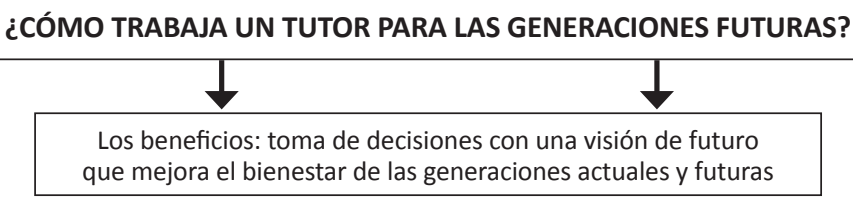

\begin{tabular}{|c|c|}
\hline Inteligencia & Incentivos \\
\hline \begin{tabular}{|c|}
\hline El tutor, como \\
defensor, transmita \\
las preocupaciones \\
de los ciudadanos \\
a las unidades \\
legislativas
\end{tabular} & $\begin{array}{c}\text { El tutor, como } \\
\text { órgano asesor, } \\
\text { recomienda } \\
\text { Soluciones }\end{array}$ \\
\hline
\end{tabular}

\begin{tabular}{|c|}
\hline Soluciones \\
\hline El tutor, como \\
una interfaz, crea \\
incentivos para \\
la integración y evita \\
la incoherencia \\
política
\end{tabular}

\begin{tabular}{|c|}
\hline Retos \\
\hline El tutor, como \\
organismo de \\
auditoría, busca los \\
conflictos de intereses \\
y los impedimentos \\
para solucionarlos \\
\hline
\end{tabular}

Fuente: Cómo incluir a las generaciones futuras en la elaboración de políticas. Future Justice

12 Tuvo una duración del año 2001 al 2006. 
Estamos, sin duda, ante un creciente escenario de creación institucional de experiencias comparadas en esta temática de búsqueda de modelos de institucionalización de la guardianía o tutoría de las FG.

\section{MARCO CONCEPTUAL SOBRE EL SISTEMA JURÍDICO Y LAS FUTURAS GENERACIONES: INTERDISCIPLINARIEDAD E INTERGENERA- CIONALIDAD JURÍDICA ${ }^{13}$}

Partimos de la consideración de asumir el Derecho de las Futuras Generaciones como un (sub) sistema jurídico en perspectiva interdisciplinaria y ambiental, $y$, en ese sentido, al menos desagregamos dos modelos metodológicos para estudiar.

\section{A. El Derecho de las Futuras Generaciones como sistema de control jurídico de las fu- turas generaciones}

En sentido amplio, el control social o mejor aún el sistema de control social representa un macromecanismo multidimensional que las sociedades generan para poder conducirse, gobernarse y orientarse organizadamente a fin de llevar a cabo la convivencia social. Se puede decir que una sociedad $x$ cuenta con (sub) sistemas de control social en la educación, el trabajo, las creencias, la economía, las familias, el lenguaje, el sistema de conocimientos, las profesiones, el arte, el entorno, etc. Dependerá del carácter abierto o cerrado (Popper) y de sus matices, el que las sociedades sean más flexibles, tolerantes, permisibles o libertarias, a partir de sus controles sociales.
Bajo esta lógica de sistemas de control social -en perspectiva intergeneracional-, identificaremos elementos como: políticas, contenidos a ser acatados o exigibles (derechos y obligaciones), agencias portadoras, respuestas a modo de sanciones (sean positivas o negativas), aspectos culturales o éticos, entre otros. Por ejemplo, en la educación identificaremos políticas sociales educativas, organizaciones sociales transmisoras y gestoras de los mandatos formativos (familia, escuela, medios de comunicación), pautas culturales que afirman, niegan o invisibilizan determinados patrones de conducta, pautas éticas sobre lo que se entienda como la correcta educación, y así podríamos seguir desarrollando.

Por lo tanto, resulta válido aludir al (sub sistema) de control social intergeneracional. ¿Cuáles serían las dimensiones o expresiones de este control social intergeneracional? Muchísimas, por ejemplo, la educación en perspectiva de los valores intergeneracionales, la economía y las herramientas intergeneracionales, las tecnologías sostenibles y los requerimientos de orden intergeneracional en relación con el ambiente entre muchas más. Variará el modo con el que tales sistemas de control social referido a lo intergeneracional adopten sus propios mecanismos por persuasión, coerción o concertación, en relación con los colectivos y personas concernidas.

En el caso del derecho y las futuras generaciones se trataría de la expresión jurídica del control social intergeneracional, ergo, "el sistema de control social jurídico referido a lo intergeneracional". Nótese la lógica de agregación o de conjuntos:

Control social general $\rightarrow$ Control social jurídico

Control social jurídico respecto las Futuras Generaciones

En conclusión, un posible enfoque sistémico del Derecho sería aquél que circunscribe a lo que hemos signado como control social jurídico del ambiente y sus diversos elementos o componentes:

\begin{tabular}{|c|c|}
\hline \multicolumn{2}{|c|}{ El Sistema jurídico como sistema de control social jurídico respecto lo intergeneracional } \\
\hline a. Doctrina & vg. La teoría del Derecho de las futuras generaciones \\
\hline b. Principios & vg. Equidad intergeneracional \\
\hline c. Políticas y conexos & $\begin{array}{l}\text { vg. La Política de Estado y Futuras Generaciones, Estrategia Nacional del Cambio Climá- } \\
\text { tico, Agenda Ambiental Nacional }\end{array}$ \\
\hline $\begin{array}{l}\text { d. Agencias, instituciones u organiza- } \\
\text { ciones }\end{array}$ & $\begin{array}{l}\text { vg. eventual Ombudsman de las Futuras Generaciones Ministerio del Ambiente; Pro- } \\
\text { grama de las Naciones Unidas para el Medio Ambiente (PNUMA); }\end{array}$ \\
\hline e. Derecho y responsabilidades; & $\begin{array}{l}\text { vg. Derechos de agricultores; responsabilidades ambientales de titulares de activida- } \\
\text { des de transporte terrestre y acuático }\end{array}$ \\
\hline $\begin{array}{l}\text { f. Destinatarios (vg. sectores, pobla- } \\
\text { ción, futuras generaciones) }\end{array}$ & $\begin{array}{l}\text { vg. Industriales manufactureros; pequeños mineros y artesanales; titulares de activi- } \\
\text { dades pesqueras y acuícolas; poblaciones indígenas }\end{array}$ \\
\hline
\end{tabular}

13 Este apartado se basa en los enfoques desarrollados en el texto: La investigación en el Derecho ambiental. Hacia una metodología de la investigación para la disertación jurídica ambiental. Trabajo inédito (Foy, 2018). 
BASES CONCEPTUALES PARA EL ESTUDIO INTERDISCIPLINARIO DEL SISTEMA JURÍDICO Y LAS FUTURAS GENERACIONES: PERSPECTIVA TEÓRICA Y EMPÍRICA DESDE EL DERECHO AMBIENTAL

\begin{tabular}{|l|l|}
\hline g. Procedimientos & $\begin{array}{l}\text { vg. Textos Únicos de Procedimientos Ambientales (TUPAs). Procedimiento Administra- } \\
\text { tivo Sancionador Ambiental (PAS) }\end{array}$ \\
\hline h. Sanciones (positivas o negativos) & vg. penas; incentivos intrageneracionales \\
\hline i. Cultura & $\begin{array}{l}\text { vg. cultura climática; cultura del reciclaje; cultura del agua, del bosque o de la monta- } \\
\text { ña; cultura urbana sostenible }\end{array}$ \\
\hline j. Ética & vg. Bioética y recursos genéticos; ética climática; ética de la justicia intergeneracional \\
\hline
\end{tabular}

Este esquema por aproximación y sin un desarrollo propiamente investigativo lo hemos sugerido en temáticas como:

- Consideraciones sobre Derecho, Bosque y Cambio climático

- $\quad$ Sistema jurídico y ciudades sostenibles

- $\quad$ Sistema jurídico y animales

- El sistema jurídico y los recursos hídricos

- $\quad$ El sistema jurídico y los residuos sólidos

Se puede complejizar esta suerte de matriz del sistema jurídico como sistema de control social jurídico referido a las futuras generaciones y de sus elementos o componentes si, por ejemplo, hacemos la correlación con la creación de mecanismos económicos contables intergeneracionales o para la creación del ombudsman de las futuras generaciones.

B. El sistema jurídico como sistema secuencial de saberes referidos a las futuras generaciones: perspectiva ambiental

En réplica o adaptación conceptual al conocido enfoque del jurista Claus Roxin para el sistema penal (2002, p. 100), podríamos señalar al sistema jurídico y las futuras generaciones en perspectiva como la secuela de "transformar los conocimientos o saberes sobre las Futuras generaciones y del desarrollo sostenible en exigencias políticas intergeneracionales y éstas a su vez, transformadas en reglas jurídico ambientales de lex lata o lege ferenda".

Gráfico 4

Esquema del Sistema jurídico como sistema secuencial de saberes referidos a las Futuras Generaciones: perspectiva ambiental

Los conocimientos o saberes sobre las Futuras generaciones

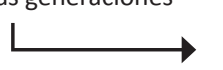

Exigencias políticas

sobre las Futuras generaciones
Otras reglas económicas, tecnológicas, educativas, etc. sobre las Futuras Generaciones etc.

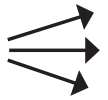

[Elaboración propia] para las Futuras generaciones

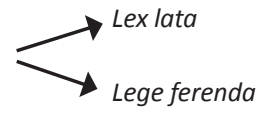

Gráfico 5

Ejemplo de aplicación del enfoque del Sistema jurídico como sistema secuencial de saberes referidos a las Futuras Generaciones: perspectiva ambiental

\section{Defensor u \\ Ombusdman de las \\ Futuras generaciones}

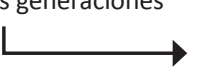

II. Políticas de Estado

sobre las Futuras generaciones

[Elaboración propia]

$\longrightarrow$

Otras pautas: económicas, tecnológicas, educativas, etc. para sostener el modelo. etc

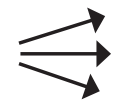

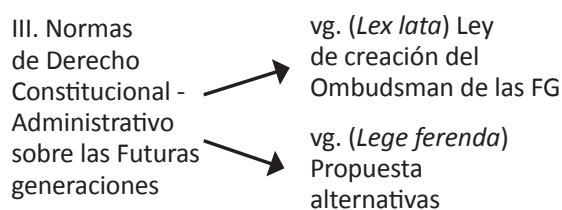

De otra lado, podemos transversalizar las diversas áreas o ramas del derecho e ir conectando (de Lex Lata o de Lege ferenda) cómo es que se van incorporando las consideraciones intergeneracionales, muchas de la cuales ya las hemos explicitado y desarrollado a la largo del presente estudio. Ver gráfico 6.
VI. DEMOSTRACIÓN DE ESCENARIO EMPÍRICO APLICATIVO INTERDISCIPLINARIO DE LO JURÍDICO INTERGENERACIONAL DESDE EL DERECHO AMBIENTAL: UN MODELO POR ARMAR

En el marco de las consideraciones expuestas, las responsabilidades hacia las FG suponen una 


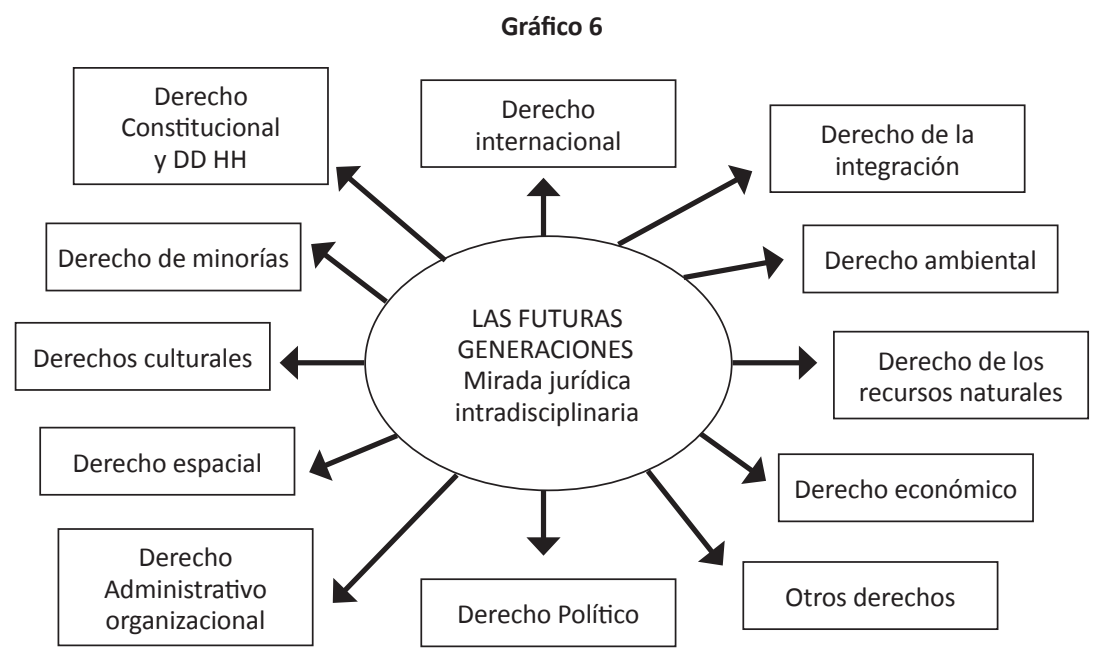

[Fuente: elaboración propia (Foy Valencia, 2016)]

perspectiva de largo plazo a diferencia de los enfoques cortoplacistas de los sistemas y políticas convencionales a los que solo les importa mostrar resultados más inmediatos y visibles. Por ello, a modo de estrategias de implementación global de las responsabilidades hacia las FG, retomamos el esquema de Edith Brown Weiss (1999, pp. 139$164)^{14}$ y lo extrapolamos a modo de ejemplo interrelacionándolo con algunas vertientes disciplinarias, bajo la premisa que no se trata de una suma compartimentalizada sino interactiva de tales disciplinas.

\begin{tabular}{|c|c|c|c|c|c|c|}
\hline & \multirow[t]{2}{*}{ Componentes } & \multicolumn{5}{|c|}{$\begin{array}{l}\text { Dimensiones interdisciplinarias } \\
\text { (Ejemplos temáticos-problemáticos) }{ }^{15}\end{array}$} \\
\hline & & $\begin{array}{l}\text { Jurídica } \\
\text { (Ej.) }\end{array}$ & $\begin{array}{l}\text { Ético-filosófico } \\
\text { (Ej.) }\end{array}$ & $\begin{array}{c}\text { Social-cultural } \\
\text { (Ej.) }\end{array}$ & $\begin{array}{c}\text { Ambiental- } \\
\text { sostenible (Ej.) }\end{array}$ & $\begin{array}{c}\text { Técnico- } \\
\text { económico (Ej.) }\end{array}$ \\
\hline 1. & $\begin{array}{l}\text { Representación } \\
\text { de las } \text { FG }^{16}\end{array}$ & $\begin{array}{l}\text { - Modelos legales } \\
\text { de organización: } \\
\text { Autoridad, Om- } \\
\text { budsman o Defen- } \\
\text { soría para las FG } \\
\text { - Fundamentos } \\
\text { político jurídicos } \\
\text { incluso constitu- } \\
\text { cionales }\end{array}$ & $\begin{array}{l}\text { - Fundamentos } \\
\text { morales de la } \\
\text { Responsabilidad } \\
\text { intergeneracional } \\
\text { - Hacia una ética } \\
\text { de lo intergenera- } \\
\text { cional }\end{array}$ & $\begin{array}{l}\text { - El pasado, pre- } \\
\text { sente y futuro } \\
\text { como un conti- } \\
\text { nuum socio cultu- } \\
\text { ral en el tiempo, } \\
\text { en un contexto } \\
\text { diacrónico y sin- } \\
\text { crónico de diver- } \\
\text { sidad }\end{array}$ & $\begin{array}{l}\text { - Conservación } \\
\text { dinámica de la } \\
\text { continuidad eco- } \\
\text { sistémica } \\
\text { - Indicadores de } \\
\text { desempeño am- } \\
\text { biental }\end{array}$ & $\begin{array}{l}\text { - Mecanismos Fi- } \\
\text { duciarios } \\
\text { - Fondo económi- } \\
\text { cos intergenera- } \\
\text { cionales } \\
\text { - Contabilidad in- } \\
\text { tergeneracional }\end{array}$ \\
\hline
\end{tabular}

14 Nota metodológica aclaratoria: Si bien la versión del texto de Edith Brown en español es del año 1999 (en realidad la versión original corresponde al año 1988), sin embargo, tales postulados y componentes estimamos que son aplicables y proyectables al presente, como de alguna manera se advierte que muchos de los enfoques del Handbook of Intergenerational Justice (Tremmel, 2016), sintonizan con los de la autora en ciernes.

15 Como hemos expresado, sólo ponemos algunas vertientes disciplinarias, quedan muchas otras no menos importantes como las de orden político, geopolítico o psicológico

16 La representación de las FG en los procesos de toma de decisiones El uso sostenible de los recursos renovables.

17 El uso sostenible de los recursos renovables.

18 "Una economía que se traduce en un mejor bienestar humano y la reducción de las desigualdades, sin exponer las generaciones futuras a riesgos ambientales significativos y de escaseces ecológicas. Es aquella que busca traer beneficios para la sociedad a largo plazo para las actividades a corto plazo destinadas a mitigar los riesgos ambientales. Una economía verde es un componente de habilitación del objetivo global del desarrollo sostenible" (UNCTAD, 2011). 


\begin{tabular}{|c|c|c|c|c|c|c|}
\hline 3. & $\begin{array}{l}\text { Mantenimiento } \\
\text { de instalaciones } \\
\text { y servicios }{ }^{19}\end{array}$ & $\begin{array}{l}\text { - Bases jurídicas } \\
\text { garantistas para } \\
\text { una infraestructu- } \\
\text { ra y servicios sos- } \\
\text { tenibles de larga } \\
\text { duración: interge- } \\
\text { neracional }\end{array}$ & $\begin{array}{l}\text { - "Infraestructuras } \\
\text { éticas }{ }^{20 "}\end{array}$ & $\begin{array}{l}\text { - Cultura y ética } \\
\text { ciudadana de la } \\
\text { responsabilidad } \\
\text { intergeneracio- } \\
\text { nal/ intra gene- } \\
\text { racional en el } \\
\text { mantenimiento } \\
\text { de instalaciones y } \\
\text { servicios }\end{array}$ & $\begin{array}{l}\text { - Infraestructuras } \\
\text { y servicios de lar- } \\
\text { ga duración: } \\
\text { Intergeneracional } \\
\text { según las mejores } \\
\text { técnicas disponi- } \\
\text { bles (MTD) }\end{array}$ & $\begin{array}{l}\text { - Costos de in- } \\
\text { fraestructuras y } \\
\text { servicios de larga } \\
\text { duración, ecoefi- } \\
\text { cientes } \\
\text { - Empresas soste- } \\
\text { nibles en infraes- } \\
\text { tructura y servi- } \\
\text { cios }\end{array}$ \\
\hline 4. & $\begin{array}{l}\text { Monitoreo del } \\
\text { patrimonio } \\
\text { natural y } \\
\text { cultural }^{21}\end{array}$ & $\begin{array}{l}\text { - Sistemas legales } \\
\text { de prevención, } \\
\text { monitoreo, reme- } \\
\text { diación, incenti- } \\
\text { vos }\end{array}$ & $\begin{array}{l}\text { - Bases para el de- } \\
\text { ber de custodia y } \\
\text { paradigma de la } \\
\text { vigilancia interge- } \\
\text { neracional }\end{array}$ & $\begin{array}{l}\text { - Participación } \\
\text { informada de las } \\
\text { poblaciones }\end{array}$ & $\begin{array}{l}\text { - Considerar e } \\
\text { integrar técnicas } \\
\text { y saberes moder- } \\
\text { nos y tradiciona- } \\
\text { les }\end{array}$ & $\begin{array}{l}\text { - Asignación de } \\
\text { costos en pers- } \\
\text { pectiva intergene- } \\
\text { racional }\end{array}$ \\
\hline 5. & $\begin{array}{l}\text { Evaluación de } \\
\text { conservación } \\
\text { intergenera- } \\
\text { cional }^{22}\end{array}$ & $\begin{array}{l}\text { - Elaborar y afinar } \\
\text { mecanismos lega- } \\
\text { les sobre los im- } \\
\text { pactos ambienta- } \\
\text { les en perspectiva } \\
\text { intergeneracional }\end{array}$ & $\begin{array}{l}\text { - Bases éticas para } \\
\text { una prospectiva } \\
\text { de los impactos } \\
\text { ambientales en } \\
\text { perspectiva inter- } \\
\text { generacional }\end{array}$ & $\begin{array}{l}\text { - El impacto social } \\
\text { - cultural en las FG }\end{array}$ & $\begin{array}{l}\text { - Dimensiones del } \\
\text { impacto ambien- } \\
\text { tal intergenera- } \\
\text { cional } \\
-\quad \text { Mecanismos } \\
\text { para su preven- } \\
\text { ción adelanta- } \\
\text { miento, correc- } \\
\text { ción }\end{array}$ & $\begin{array}{l}\text { - Asignación de } \\
\text { costos en pers- } \\
\text { pectiva intergene- } \\
\text { racional }\end{array}$ \\
\hline 6. & $\begin{array}{l}\text { Investigación } \\
\text { y desarrollo } \\
\text { científico y } \\
\text { tecnológico }{ }^{23}\end{array}$ & $\begin{array}{l}\text { - Desarrollar mar- } \\
\text { co legal garantis- } \\
\text { ta impulsor para } \\
\text { este componente } \\
\text { de lo intergenera- } \\
\text { cional }\end{array}$ & $\begin{array}{l}\text { - Bases ético - filo- } \\
\text { sófica de la cien- } \\
\text { cia y tecnología } \\
\text { en perspectiva } \\
\text { holística para la } \\
\text { afirmación del } \\
\text { paradigma de la } \\
\text { sostenibilidad in- } \\
\text { tergeneracional }\end{array}$ & $\begin{array}{l}\text { - Integración de } \\
\text { saberes, conoci- } \\
\text { mientos y tecno- } \\
\text { logía moderna y } \\
\text { tradicional para } \\
\text { los intereses inter- } \\
\text { genera- cionales }\end{array}$ & $\begin{array}{l}\text { - Bases ecológicas } \\
\text { para la afirmación } \\
\text { del paradigma de } \\
\text { la sostenibilidad } \\
\text { intergeneracional }\end{array}$ & $\begin{array}{l}\text { - Indicadores anti- } \\
\text { cipativos y costos } \\
\text { de los impactos } \\
\text { ambientales inter- } \\
\text { generacionales } \\
\text { - Aplicación de las } \\
\text { TIC en perspectiva } \\
\text { intergeneracional }\end{array}$ \\
\hline 7. & Coificación ${ }^{24}$ & $\begin{array}{l}\text { - Sistematización } \\
\text { y formalización de } \\
\text { los componentes } \\
\text { jurídicos para una } \\
\text { Justicia Intergene- } \\
\text { racional } \\
\text { - Derecho Interge- } \\
\text { neracional com- } \\
\text { parado } \\
\text { - Jurisprudencia } \\
\text { intergeneracional }\end{array}$ & $\begin{array}{l}\text { - Sustentar que las } \\
\text { FG sean parte de } \\
\text { la comunidad mo- } \\
\text { ral de intereses } \\
\text { - Fundamentación } \\
\text { de los diferentes } \\
\text { modelos sobre la } \\
\text { justicia intergene- } \\
\text { racional }\end{array}$ & $\begin{array}{l}\text { - Considerar los } \\
\text { intereses de lo } \\
\text { intergeneracional } \\
\text { de la diversidad } \\
\text { socio cultural ur- } \\
\text { bano rural y global }\end{array}$ & $\begin{array}{l}\text { - Garantizar una } \\
\text { normativa in- } \\
\text { tergeneracional } \\
\text { investida de sus- } \\
\text { tentos económi- } \\
\text { cos- ecológicos }\end{array}$ & $\begin{array}{l}\text { - Garantizar una } \\
\text { normativa in- } \\
\text { tergeneracional } \\
\text { investida de sus- } \\
\text { tentos económi- } \\
\text { cos-ecológicos y } \\
\text { de costos interge- } \\
\text { neracional }\end{array}$ \\
\hline
\end{tabular}

19 Mantenimiento de instalaciones y servicios, incluyendo aquellas para la conservación de los recursos naturales y culturales y para la recopilación, almacenado y recuperación de información.

20 "Para la OCDE (1997) la infraestructura ética de una sociedad está conformada por una serie de factores que van a posibilitar la adecuada gestión de las conductas de los empleados y servidores públicos: Apoyo político, un marco legal eficaz, adecuados mecanismos de socialización profesional, una sociedad civil madura, activa y vigilante y sistemas y procedimientos de control". Recuperado de:http://dirpersonasyadmonpublica.blogspot.pe/2013/10/infraestructura-eticaen-la-actualidad.html

En este caso empleamos en un sentido más restrictivo y "duro" el alcance del término infraestructura.

21 El monitoreo de la diversidad de los recursos naturales y culturales, y la calidad ambiental.

22 La evaluación del impacto ambiental de nuestras acciones sobre la conservación del planeta y el patrimonio cultural para las FG.

23 La investigación científica y desarrollo tecnológico para comprender los efectos de nuestras acciones, para desarrollar recursos alternativos, y para incrementar la eficiencia en la explotación de nuestros recursos naturales y culturales.

24 La codificación de derechos y obligaciones planetarias y de los deberes legales internacionales con ellos asociados para recursos y funciones específicas; $y$ 


\begin{tabular}{|c|c|c|c|c|c|c|}
\hline 8. & Educación ${ }^{25}$ & $\begin{array}{l}\text { - Formación legal } \\
\text { a los segmentos } \\
\text { de la sociedad } \\
\text { sobre las nuevas } \\
\text { relaciones "man- } \\
\text { do - obediencia", } \\
\text { "derechos - "de- } \\
\text { beres" del nuevo } \\
\text { paradigma regu- } \\
\text { latorio de lo inter- } \\
\text { generacional }\end{array}$ & $\begin{array}{l}\text { - Bases éticas para } \\
\text { la formación del } \\
\text { "homo inter gene- } \\
\text { racional" }\end{array}$ & $\begin{array}{l}\text { - Formación inte- } \\
\text { gral, diversificada } \\
\text { e interdisciplinaria } \\
\text { sobre los valores } \\
\text { ambientales y los } \\
\text { intergeneracio- } \\
\text { nales }\end{array}$ & $\begin{array}{l}\text { - Formación inte- } \\
\text { gral e interdisci- } \\
\text { plinaria al servicio } \\
\text { de la sostenibili- } \\
\text { dad y los valores } \\
\text { de lo intergenera- } \\
\text { cional }\end{array}$ & $\begin{array}{l}\text { - Redes de segui- } \\
\text { miento e inter- } \\
\text { cambio de infor- } \\
\text { mación ambiental } \\
\text { - Sistema de cos- } \\
\text { tos para tales re- } \\
\text { des y mecanismos }\end{array}$ \\
\hline
\end{tabular}

[Elaboración propia]

En realidad, lo que hemos configurado es una primera matriz metodológica para el estudio interdisciplinario del sistema jurídico y las futuras generaciones en aplicación al Derecho Ambiental. Sin embargo, no es sino una primera aproximación que requiere afinamiento y un desarrollo investigativo más minucioso Así, por ejemplo, si solo nos atuviéramos en términos meramente disciplinarios a lo jurídico, podríamos derivar otras matrices complementarias: una primera, en términos de desagregado de los elementos de un sistema jurídico y su aplicación en relación a los componentes de lo intergeneracional según Brown (1999); y, una segunda, conectándolo interdisciplinariamente con las diversas áreas del derecho, identificando transversalmente la inserción progresiva y creciente de lo intergeneracional en las modernas estructuras legales (Derecho intergeneracional comparado).

En relación con la primera correlación solo seleccionaremos tres componentes de los estimados por Brown Weiss:

\begin{tabular}{|c|c|c|c|}
\hline Política & $\begin{array}{l}\text { - Independencia } \\
\text { - Legitimidad } \\
\text { - Transparencia } \\
\text { - Accesibilidad }{ }^{13} \\
\text { - Acceso a la Información }\end{array}$ & $\begin{array}{l}\text { 1. Transectorialidad } \\
\text { 2. Análisis costo - beneficio } \\
\text { 3. Competitividad } \\
\text { 4. Gestión por resultados } \\
\text { 5. Seguridad jurídica } \\
\text { 6. Mejora continua } \\
\text { 7. Cooperación público-privada }\end{array}$ & $\begin{array}{l}\text { - Bases legales para una po- } \\
\text { lítica sobre los derechos de } \\
\text { las futuras generaciones }\end{array}$ \\
\hline Principios & $\begin{array}{l}\text { - Principio de Equidad intergenera- } \\
\text { cional } \\
\text { Concordar con los } 5 \text { principios de jus- } \\
\text { ticia generacional de Lumer ( } 2006 \text { : } \\
\text { 39-45) } \\
\text { - Principio 1: hedonismo ético, orien- } \\
\text { tación de bienestar } \\
\text { - Principio 2: universalismo de los be- } \\
\text { neficiarios } \\
\text { - Principio 3: Prioritarismo (o visión } \\
\text { de prioridad) } \\
\text { - Principio 4: Principio de compromi- } \\
\text { so limitado } \\
\text { - Principio 5: Eficiencia o principio de } \\
\text { economía }\end{array}$ & $\begin{array}{l}\text { Ejemplos: } \\
\text { - Sostenibilidad intergeneracional } \\
\text { - Prevención y precaución } \\
\text { - Responsabilidad por daño }\end{array}$ & $\begin{array}{l}\text { Principio de Equidad interge- } \\
\text { neracional desagregado en } \\
\text { (1992, Brown Weiss): } \\
\text { - Conservación de opciones } \\
\text { - Conservación de la calidad } \\
\text { - Conservación de acceso }\end{array}$ \\
\hline
\end{tabular}

25 El aprendizaje y la educación globales para elevar el grado de conciencia pública de todos los pueblos y de personas de todas las edades, acerca de la necesidad de conservar el plante y nuestros recursos culturales para las FG.

26 Tomado de Science and Environmental Health Network y The International Human Rights Clinic at Harvard Law School (2008). 


\begin{tabular}{|c|c|c|c|}
\hline Organización & $\begin{array}{l}\text { Ejemplos: } \\
\text { - Hungría (2007): Comisionado Par- } \\
\text { lamentario para las Generaciones } \\
\text { Futuras. - Bélgica: Fundación para las } \\
\text { Generaciones Futuras } \\
\text { - Israel: Comisión para las Futuras } \\
\text { Generaciones - Knesset Commissio- } \\
\text { ner of Future Generations. } \\
\text { - Nueva Zelanda: Comisionado Par- } \\
\text { lamentario para el Medio Ambiente } \\
\text { (Guardián de la Perspectiva a Largo } \\
\text { Plazo: Guardian of the Long View). } \\
\text { - Finlandia: Comité Parlamentario } \\
\text { para el Futuro }\end{array}$ & $\begin{array}{l}\text { - Ministerios Ambientales o del } \\
\text { Desarrollo Sostenible } \\
\text { - Unidades de gestión ambiental } \\
\text { sectorial o transectorial respecto } \\
\text { los recursos naturales renovables }\end{array}$ & $\begin{array}{l}\text { - Bases legales para la orga- } \\
\text { nización y gestión de los de- } \\
\text { rechos de las FG. } \\
\text { - Modelos legales organiza- } \\
\text { cionales sobre el Ombuds- } \\
\text { man de las FG }\end{array}$ \\
\hline $\begin{array}{l}\text { Derechos y } \\
\text { deberes }\end{array}$ & $\begin{array}{l}\text { - Deber de representación de las FG } \\
\text { - Derechos intergeneracionales }\end{array}$ & $\begin{array}{l}\text { - Sustentación jurídica de las obli- } \\
\text { gaciones de sostenibilidad hacia } \\
\text { las FG }\end{array}$ & $\begin{array}{l}\text { - Sustentación de Derechos y } \\
\text { Deberes en relación con las } \\
\text { FG y su legitimación - Posibi- } \\
\text { lidades que ofrece un marco } \\
\text { teórico contractual para in- } \\
\text { cluir a las FG en la comuni- } \\
\text { dad moral CM y así justificar } \\
\text { estas obligaciones o dere- } \\
\text { chos (Loewe, 2010) }\end{array}$ \\
\hline Responsabilidades & $\begin{array}{l}\text { - Responsabilidad intergeneracional } \\
\text { - Promover la solidaridad intergene- } \\
\text { racional por las necesidades de las } \\
\text { FG }\end{array}$ & $\begin{array}{l}\text { - Responsabilidades comunes } \\
\text { pero diferenciadas en perspecti- } \\
\text { va intergeneracional }\end{array}$ & $\begin{array}{l}\text { - Construcción de una sus- } \\
\text { tentación legal sobre las } \\
\text { responsabilidades interge- } \\
\text { neracionales: alcances y li- } \\
\text { mitaciones reales }\end{array}$ \\
\hline Ética & $\begin{array}{l}\text { - Bases éticas sobre la equidad inter- } \\
\text { generacional en relación con estos } \\
\text { tres componentes }\end{array}$ & & \\
\hline
\end{tabular}

[Elaboración propia]

\section{EVALUACIÓN DE CONJUNTO}

La motivación por la relación entre el sistema jurídico y las futuras generaciones, y su perspectiva ambiental obedece a una larga conexión temática y problemática que ancla en raíces histórico-culturales de larga duración, pero que en tiempos recientes adquiere una dimensión más ostensible y globalizada, no solo en los escenarios académicos, sino también en los socio-políticos y de la ciudadanía global.

Los sistemas jurídicos nacional e internacional han sido impactados y transversalizados por consideraciones de orden transgeneracional, haciéndose eco de la relevancia que ello tiene en nuestros días aquellos términos los cuales no sirven únicamente para responder ante las necesidades de las poblaciones venideras, sino también para la continuidad de los ecosistemas. La ampliación del límite de la comunidad moral a toda la comunidad biótica (léase poblaciones futuras, ecosistemas, seres vivos) ha conducido a que se activen creativamente las herramientas y mecanismos jurídicos y la emergencia de propuestas novedosas (lex lata y lege ferenda).

Es el caso que estos procesos y fenómenos no son unidisciplinarios, sino, al contrario, de orden interdisciplinario, y, en ese contexto, la relación entre estos nuevos desafíos intergeneracionales y la cuestión jurídico-ambiental devienen en inescindibles. Ello nos ha conducido a elaborar y desarrollar un modelo sistémico para el estudio del sistema jurídico y las FG en perspectiva ambiental, que como lo anunciamos es una suerte de modelo para armar.

No estamos ante pretensiones teoréticas sino contribuyendo a sentar bases para afrontar desafíos crecientes que además se enraízan con tradiciones ancestrales y requerimientos actuales y futuros.

Hemos querido aportar modestamente estas primeras aproximaciones a un tema que aún tienen mucho por recorrer.

\section{CONCLUSIONES}

a) La presente investigación ha tenido como objetivo sentar, en nuestro medio local, las bases preliminares para el estudio interdisciplinario del sistema jurídico en relación con las futuras generaciones. Precisamente, las sostenemos a modo de fuentes materiales del Derecho de las Futuras generaciones; esto es, aplicado conceptual y "empíricamente" al Derecho ambiental (intergeneracional). 
b) Carecemos de un modelo integral y sistémico que aborde el desafío jurídico e interdisciplinario en relación con las futuras generaciones.

c) Una primera consideración antes que nada es tener claras las razones del por qué abocarse a este concepto y fenómeno aparentemente difuso, lo cual pasa por una comprensión interdisciplinaria del mismo, a modo de fuentes materiales del derecho y las FG.

d) Los sistemas de control social en perspectiva intergeneracional igualmente vienen recibiendo y generando alternativas de orientación de conductas en perspectiva intergeneracional, aunque no en la intensidad requerida.

e) A su turno, los sistemas jurídicos nacional e internacional bajo diferente modo, ritmo e interés vienen produciendo desde sus distintos instrumentos y mecanismos constitucionales normas, sistemas de protección y prevención para responder a estos desafíos, segregando e innovando fórmulas y respuestas.

f) Hemos elaborado metodológicamente algunas matrices sistémicas para encuadrar interdisciplinaria e intradisciplinariamente la cuestión de las FG en relación con los sistemas jurídicos.

g) El marco metodológico para la presente investigación se basa en el texto "La investigación en el Derecho ambiental. Hacia un metodología de la investigación para la disertación jurídica ambiental"27, a partir del cual se ha elaborado un marco metodológico para el estudio interdisciplinario del sistema jurídico en relación con las FG, así como algunos alcances conceptuales como objeto y realidad a modo de fuentes materiales del derecho y las FG.

h) Los fundamentos del sistema jurídico en relación con las FG, incluyendo la referencia constitucional, son abordaos ejemplificativamente a partir de ciertos ejes como la justicia intergeneracional, el interés intergeneracional y la comunidad moral, la representación de las FG ombudsman o defensor de las FG.

i) El marco conceptual sobre el sistema jurídico y las FG es abordado en términos de inter- disciplinariedad e intergeneracionalidad jurídica a partir de dos modelos: El Derecho de las Futuras Generaciones como sistema de control jurídico de las futuras generaciones y el sistema jurídico como sistema secuencial de saberes referidos a las Futuras generaciones: perspectiva ambiental.

j) Por último, elaboramos una demostración de escenario empírico aplicativo interdisciplinario de lo jurídico intergeneracional desde el Derecho ambiental: un modelo por armar, como ya lo expresamos.

\section{REFERENCIAS}

Arribas Herguedas, F. (2009). Sostenibilidad ecológica, justicia intergeneracional y democracia liberal. En: Asociación Española de Ética y Filosofía Política y Departamento de Filosofía moral de la Universidad de Murcia (Coord. y Compil.). XVI Semana de Ética y Filosofía Política-Congreso Internacional: Presente, pasado y futuro de la democracia. Madrid: Universidad Rey Juan Carlos, pp. 405-413.

Armas Morales, C. y J. Anicama Pescorán (2014). Interacciones de la prospectiva y los derechos intergeneracionales para un ambiente humano sostenible. En: Pensamiento Crítico 19. Recuperado de: http://revistasinvestigacion.unmsm.edu.pe/index.php/econo/article/ view/11099/9978

Beneite Martí, J. (2013). El problema de la noidentidad en la justicia intergeneracional y el enfoque de la bioética hermenéutica prospectiva. En: Domingo Moratalla, T. y A. Domingo Moratalla (editores). Bioética y hermenéutica: La ética deliberativa de Paul Ricoeur. Actas del Congreso internacional del año 2013. Valencia: Hermes-Sociedad para el Estudio Multidisciplinario de la Racionalidad y la ética hermenéutica.

Beneite Martí, J. (2014). Propuestas para una justicia intergeneracional omnicomprensiva. En: Revista de Ecología Política 46. Recuperado de: http://www.ecologiapolitica.info/?p=1145

Beneite, J.M. (2014). En diálogo con el futuro: ecología política y justicia intergeneracional. En: Papeles de relaciones ecosociales y cambio global 127, pp. 15-26.

27 En edición para su publicación en el primer cuatrimestre del año 2019 por el INTE-PUCP. 
Brown Weiss, E. (1990). Our Rights and Obligations to Future Generations for the Environment. Washington D.C.: Georgetown University Law Center.

Brown Weiss, E. (1992). Intergenerational equity: a legal framework for global environmental change. Environmental change and international law: New challenges and dimensions. Tokio: United Nations University Press.

Brown Weiss, E. (1999). Un Mundo justo para las futuras generaciones: derecho internacional, patrimonio común y equidad intergeneracional. Madrid: Mundi Prensa Libros.

Cambrón Infante, A. Voz "Generaciones futuras (jurídico)". En: Romeo Casabona, C.M. (Dir.). (2011). Enciclopedia de bioderecho y bioética I (a-h). Recuperado de: http://enciclopediabioderecho.com/voces/165

Cousteau, J. (1979). A Bill of Rights for Future Generations. En: Proceedings 34, Nueva York: The Myrin Institute.

Chabal, A. (2017). L'écocide, premier pas vers un droit des générations futures? Recuperado de https://usbeketrica.com/article/l-ecocidepremier-pas-vers-un-droit-des-generationsfutures

De Siqueira, J.E. (2001). El principio de responsabilidad de Hans Jonas. En Acta bioethica 7. Doi: 10.4046

Depauld, A. (2016). Sans-voix: Comment les inclure en politique? Le défi des générations futures et des animaux non humains (Memorial presentado para obtener el grado de Magíster en Artes en Filosofía). Montreal: Departamento de Filosofía de la Facultad de Artes y Ciencias de la Universidad de Montreal.

Dierksmeier, C. (2006). John Rawls on the rights of future generations. En: Tremmel, J.C. (Ed.) Handbook of Intergenerational Justice. Cheltenham y Northampton: Edward Elgar, pp. 72-85.

Diotallevi G. (2013). Future generazioni (tesis presentada para obtener el grado de Doctor en ricerca in Diritto Europeo su base storicocomparatistica). Roma: Scuola Dottorale Tulio Ascarelli - Università degli Studi "Roma Tre". Recuperado de: http://dspace-roma3.caspur. it/bitstream/2307/4623/1/future\%20generazioni\%20-\%20copia\%20(2).pdf
Eliade, M. (1972). El mito del eterno retorno. Madrid: Alianza Editorial.

Ferrer Ortega, L.G. (2014). Los derechos de las futuras generaciones desde la perspectiva del derecho internacional: el principio de equidad intergeneracional. México: Universidad Nacional Autónoma de México.

Ferrer Ortega, L.G. y Ferrer Ortega, J.G. (2008). El problema de la fundamentación filosófica de los derechos de las generaciones futuras. En: Anuario Mexicano de Derecho Internacional VIII, pp. 487-507.

Fernández Sánchez, L. y M. Gutiérrez Arzaluz (2013). Bienestar Social, Económico y Ambiental para las Presentes y Futuras Generaciones. En: Información tecnológica 24, pp. 121-130.

Fernández Santos, Y. (2005). Evaluación de la equidad intrageneracional e intergeneracional en una entidad pública local a través de indicadores de gestión. En: IX Congresso Internacional de Custos, celebrado del 28 a 30 de noviembre. Florianópolis.

Fracchia, F. (2010). Sviluppo sostenibile e diritti delle generazioni future. En: Rivista quadrimestrale di diritto dell'ambiente 2010-0. Recuperado de: http://www.rqda.eu/f-fracchiasviluppo-sostenibile-e-diritti-delle-generazioni-future/

Foy Valencia, P. Consideraciones políticas y jurídicas internacionales para la creación de un mecanismo defensorial (Ombudsman) de las futuras generaciones En: Ministerio del Ambiente (2015). Exposición en el Seminario Internacional: Cambio climático, sustentabilidad y equidad intergeneracional. Lima: Ministerio del Ambiente de la República del Perú, Parlamento Andino y Pontificia Universidad Javeriana.

Foy Valencia, P. (2016). El Derecho Ambiental y las futuras generaciones. En: Boletín del Grupo de Investigación de Derecho Ambiental 1 pp. 3-6. Recuperado de: http://repositorio.pucp.edu. pe/index/handle/123456789/69869

García Gutiérrez, B. (2016). ¿Nivel de vida o calidad de vida? Reseña de Un mundo justo para las futuras generaciones, de Edith Brown Weiss. En: Revista Jurídica de la Universidad Autónoma de Madrid 4, pp. 213-225.

Gaillard, E. (2015). Crimes against future generations. En: e-Pública Revista eletrónica de Direito Público 2(2). Recuperado de: http:// 
www.scielo.mec.pt/scielo.php?script $=$ sci_ arttext\&pid=S2183-184X2015000200004

Gaillard, E. (2011). Générations futures et droit privé - Vers un droit des générations futures. París: Librairie Générale de Droit et de Jurisprudence y Centre de recherche juridique Pothier de l'Université d'Orléans.

Garrido Peña, F. (2011). La ética ecológica. En: Revista Andaluza de Ciencias Sociales 10, pp. 13-19.

George, C.J. (2012). Justicia intergeneracional: la satisfacción de las necesidades y no de la codicia. En: Informe de Social Watch - El derecho a un futuro. Recuperado de: http://www.sociaIwatch.org/sites/default/files/Justicialntergeneracional2012_esp.pdf

Giraldo Betancur, P.C. (2005). Un aporte de la sociología a la temática ambiental: de la mirada sociológica a la mirada socioambiental. En: Revista Luna azul 21. Recuperado de: http://www. redalyc.org/articulo.oa?id=321727223003

Golovanevsky, L. (2007). Vulnerabilidad y transmisión intergeneracional de la pobreza. Un abordaje cuantitativo para Argentina en el siglo xxi. Buenos Aires: Universidad de Buenos Aires.

Gómez Franco, I. (2015). El enfoque de las capacidades y la justicia intergeneracional (Tesis para obtener el grado de Doctor). Madrid: Departamento de lógica, historia y filosofía de la ciencia. Universidad Nacional de Educación a Distancia.

Göpel, M. (2010). Guarding our Future: How to Protect Future Generations. En: Solutions Journal 1 (6), pp. 62-70. Recuperado de: https://www. thesolutionsjournal.com/article/guarding-ourfuture-how-to-protect-future-generations/

Göpel, M. y M. Arhelger (2010). How to Protect Future Generations' Rights in European Governance. En: Intergenerational Justice Review 10, pp. 4-10.

Göpel, M. y C. Pearce (2014). Cómo incluir a las generaciones futuras en la elaboración de políticas. Fundación World Future Council, abril de 2014.

Gosseries, A. (2008). Lo scetticismo sui diritti della generazioni future è giustificato? En: Bifulco, R. y A. d'Aloia (Coords.). Un diritto per il futuro: Teorie e modelli dello svilluppo sostenibile e deIla responsabilità intergenerazionale. Nápoles: Casa Editrice Dott. Eugenio Jovene.
Gosseries, A. (2008). On Future Generations' Future Rights. En: The Journal of Political Philosophy 16, pp. 446-474.

Gosseries, A. (2012). La cuestión generacional y la herencia rawlsiana. En: Revista Electrónica del Instituto de Investigaciones Ambrosio L. Gioja 6 (8).

Gosseries, A. y M. Hungerbühler (2006). Rule Change and Intergenerational Justice. En: Tremmel J.C. (Ed). The Handbook of Intergenerational Justice. Cheltenham y Northampton: Edward Elgar Publishing.

Gosseries, A. y I. González Ricoy (2015). Teorías de la justicia intergeneracional. Una sinopsis. En: Revista jurídica Universidad Autónoma de Madrid, Número 32, pp. 217-237.

Gosseries, A. y L. Meyer (Eds.) (2009). Intergenerational Justice. Oxford: Oxford University Press.

Guimarães, R. (2002). La ética de la sustentabilidad y la formulación de políticas de desarrollo. En: Ecología Política. Naturaleza, sociedad y utopía. Buenos Aires: CLACSO.

Häberle, P. (2009). Un derecho constitucional para las futuras generaciones. La otra forma del contrato social: El contrato generacional. En: Lecciones y Ensayos. Número 87, pp. 17-37. Recuperado de: http://www.derecho.uba.ar/ publicaciones/lye/revistas/87/lecciones-y-ensayos-87-paginas-17-37.pdf

Howarth, R. y R. Norgaard (1990). Intergenerational Resource Rights, Efficiency, and Social Optimality Land Economics. En: Land Economics 66 , pp. 1-11.

Kiss, A. (1998). L'irréversibilité et le droit des générations futures. En: Revue Juridique de I'Environnement. 23, pp. 49-57. Recuperado de: http://www.persee.fr/doc/rjenv_0397-0299_ 1998_hos_23_1_3478

Jonas, H. (1966). The phenomenon of life: toward a philosophical biology. Nueva York: Harper and Row.

Lema Añón, C. (2015). La reciprocidad indirecta y las generaciones futuras. En: Anuario de Filosofía del Derecho XXXI, pp. 203-226.

León Jiménez, F. (2009). ¿Derechos ambientales de las generaciones futuras? Medio Ambiente y Derecho. En: Revista electrónica de derecho ambiental 18. Recuperado de: http://huespedes.cica.es/gimadus/ 
Loewe, D. (2010). Obligaciones hacia generaciones futuras: El caso contractual. En: Veritas 55, pp. 21-66. Recuperado de: http://revistaseletronicas.pucrs.br/ojs/index.php/veritas/article/ viewFile/7322/5284

López Quiroz, A. (2014). Generaciones futuras y personalidad jurídica. En: Díkaion 23, pp. 251-275. Recuperado de: http://dikaion.unisabana.edu.co/index.php/dikaion/article/ view/3655/3814. Doi: 10.5294.

Lumer, C. (2006). Principles of Generational Justice. En: Handbook of Intergenerational Justice. pp. 39-52. Cheltenham y Northampton: Edward Elgar.

MacFarlane, K. (1998). Los derechos humanos de las generaciones futuras (La contribución jurídica de J. Cousteau). En: Ú/tima década 8, pp. 145-165. Recuperado de: http://www.cidpa.cl/ wp-content/uploads/2013/05/8.8-Farlane.pdf

Mank, B. (2009). Standing and Future Generations: Does Massachusetts v. EPA Open Standing for Generations to Come? En: Columbia Journal of Environmental Law 34, pp. 1-95. Recuperado de: http://scholarship.law.uc.edu/fac_pubs/272

Martin, M.J. (2012). "5 Ways to Protect the Rights of Future Generation". En: Yes! Magazine Recuperado de: https://www.yesmagazine.org/ planet/5-ways-to-protect-the-rights-of-futuregenerations

Oficina de Comunicaciones del Ministerio del Ambiente (2016). La ruta hacia el crecimiento verde. Hacia un modelo de crecimiento económico ambientalmente sostenible (2011-2016). Lima: Ministerio del Ambiente.

Ogé, F. (2014). Introduction aux Concepts et Principes du Droit de l'Environnement. Materiales pedagógicos para un módulo de la Université Virtuelle Environnement et Développement Durable. Recuperado de: https://hal.archivesouvertes.fr/hal-01258436

Ban, Ki-Moon (2013). Intergenerational solidarity and the needs of future generations. Reporte leído como ítem 19 (a) de la Agenda provisional en la Sexagésimo Octava Sesión de la Aasamblea General de las Naciones Unidas, el 15 de agosto de 2013. Recuperado de: https://www.futurejustice.org/wp-content/ uploads/2013/10/N1342845.pdf

Ost, F. y M.V. Hoecke (1990). Del contrato a la transmisión. Sobre la responsabilidad hacia las generaciones futuras. En: DOXA: Cuadernos de filosofía del derecho 22, pp. 607-630.

Padilla Rosa, E. (2002). Equidad intergeneracional y sostenibilidad. Las generaciones futuras en la evaluación de políticas y proyectos (tesis para optar por el grado de Doctor, dirigida por Joan Pasqual y Rocabert). Barcelona: Universidad Autónoma de Barcelona.

Padilla Rosa, E. (2000). Equidad intergeneracional y sostenibilidad. En: Febrero Paños, E.; Cadarso, M.A.; Córcoles Fuentes, C.; de Juan Asenjo, Ó.; de la Peña Alonso, E.; López Santiago, L.A.; Rieta Sánchez, E. y C. Sánchez Alegre. VII Jornadas de Economía Crítica. Madrid: Facultad de Ciencias Económicas y Empresariales de Albacete, Universidad de Castilla-La Mancha. Recuperado de: http://webs.ucm.es/info/ec/ jec7/pdf/com1-11.pdf

Pajares Garay, E. y C. Loret De Mola (2015). Clima, guardianía de la Tierra y equidad intergeneracional: nuestras memorias del futuro. En: Mendoza V., Iván (comp.) Perú Hoy. Hacia otro desarrollo. Lima: DESCO-Centro de Estudios y Promoción del Desarrollo. Recuperado de: http://www.desco.org.pe/recursos/site/files/ contenido/28/09_pajares_ph_dic_15.pdf

Panario, D. y Gutiérrez, O. (2005). Medio ambiente y recursos naturales, responsabilidades con las generaciones futuras. Voces en el Fénix. En: Revista del Plan Fénix 6 (43). Recuperado de: http://www.vocesenelfenix.com/sites/default/ files/pdf/10_21.pdf

Pasqual y Rocabert, J. y G. Souto Nieves (2003). La sostenibilidad en la gestión medio ambiental. En: X Encuentro de Economía Pública: Hacienda pública y convergencia europea. Santa Cruz de Tenerife: Universidad de La Laguna.

Raffensperger, C. (2015). Resources for the legal right of future generations to inherit a livable earth. En: Science and environmental health network. Recuperado de: http://sehn.org/ wp-content/uploads/2012/12/future-gen-biblio-2015.pdf

Raffensperger, C. (2013). Guardians of Future Generation. En: Kosmos (Fall/Winter), pp. 9-13. Recuperado de: http://sehn.org/wp-content/ uploads/2013/11/Raffensperger-Kosmos-Article.pdf

Raffensperger, C. y D. Nierenberg (2013). Resources for the legal right of future generations to inherit a livable earth compiled. En: Scien- 
ce and environmental health network (junio). Recuperado de: https://celebratewcffg.files. wordpress.com/2013/09/rights-of-future-generations-annotated-bibliography.pdf

Riechmann Fernández, J. (2003). Tres principios básicos de justicia ambiental. Revista Internacional de Filosofía Política 21, pp. 103-120. Recuperado de: http://e-spacio.uned.es/fez/ eserv.php?pid=bibliuned:filopoli-2003-211117\&dsID=pdf

Riechmann Fernández, J. (2005). Responsabilidad hacia las generaciones futuras (en el contexto de la crisis ecológica). En: Un mundo vulnerable: ensayos sobre ecología, ética y tecnociencia. Madrid: Los libros de la Catarata.

Robles Garza, M.Y. (2010). Los derechos de las futuras generaciones desde la perspectiva de los derechos humanos. En: Jurídica-Anuario del Departamento de Derecho de la Universidad Iberoamericana 40, pp. 71-90.

Roxin, K. (2002). Política criminal y sistema del derecho penal. Buenos Aires: Hammurabi.

Santacoloma Méndez, L.J. (2014). Las generaciones futuras como sujetos de Derecho (Tesis para optar el grado de Magíster). Buenos Aires: Universidad de Palermo.

Saruwatari Zavala, G. (2009). Origen del concepto de generaciones futuras en el derecho internacional de los derechos humanos. En: Revista del Centro Nacional de Derechos Humanos 4(10), pp. 29-56.

Sayed Sikandar, S. H. (2002). Principles of Environmental Law in Islam. En: Arab Law Quarterly 17(3), pp. 241-254.

Science and Environmental Health Network e International Human Rights Clinic (2008). Models for Protecting the Environment for Future Generations. Cambridge: Harvard Law School. Recuperado de: http://hrp.law.harvard.edu/ wp-content/uploads/2013/02/Models_Future_Generations.pdf

Serres, M. (1991). El contrato natural. Valencia: Pre-textos.

Sikandar, S. (2002). Principios de la ley islámica sobre el medio ambiente. En Arab Law Quarterly 17(3), pp. 241-254. Recuperado de: http:// es.truth-seeker.info/joyas-del-islam/principios-la-ley-islamica-medio-ambiente/
Summers, J.K. y L.M. Smith (2014). The Role of Social and Intergenerational Equity in Making Changes in Human Well-Being Sustainable. En: Ambio, pp. 718-728. Recuperado de: https://www.ncbi. nlm.nih.gov/pubmed/24402649. Doi: 10.1007.

Soro Mateo, B. (2012). Nuevos retos del derecho ambiental desde la perspectiva del Bioderecho: Especial referencia a los derechos de los animales y de las futuras generaciones. En: Revista VIA IURIS 13, pp. 105-122.

Thompson, D. (2010). Representing future generations: political presentism and democratic trusteeship. En: Critical Review of International and Political Philosophy 13, pp. 17-37.

Tremmel, J.C. (ed.) (2006). Handbook of Intergenerational Justice. Cheltenham y Northampton: Edward Elgar.

Tremmel, J. C. (2009). A Theory of Intergenerational Justice. Londres: Earthscan.

Unruh, C. (2016). Present Rights for Future Generations. En: Kriterion Journal of Philosophy 30, pp. 77-92. Recuperado de: http://www.kriterion-journal-of-philosophy.org

Vial, E. (2003). Le concept de responsabilité envers les générations futures dans la gestion et le stockage des déchets radioactifs. En: Droit Nucléaire 74, pp. 15-25. Recuperado de: https:// oecd-nea.org/law/nlbfr/nlb-74/015-025.pdf

Videla, L. (2002). La Justicia Intergeneracional. Buenos Aires: CIAFIC Ediciones. Recuperado de: http://www.ciafic.edu.ar/documentos/Videla_2001.htm

Visionary Science, Ethics, Law and Action in the Public Interest (s/f). Guardianship of Future Generations. Recuperado de: http://sehn.org/ guardianship-of-future-generations/\#The_ Law_of_Future_Generations

Weston, B. y T. Bach (2009). Recalibrating the Law of Humans with the Laws of Nature: Climate Change, Human Rights, and Intergenerational Justice. En: Vermont Law School Legal Studies Research Series Research Paper 10-06: Universidad de Vermont y Universidad de lowa. Recuperado de: http://sehn.org/wp-content/ uploads/2012/12/Recalibrating-future-gen.pdf

Westra, L. (2005). Asegurar los regalos de la Tierra para generaciones presentes y futuras. Un ensayo temático que se refiere al Principio 4 sobre la legislación referente al daño a la na- 
turaleza. En: Blaze Corcoran, P.; Vilela, M. y A. Roerink (Ed.) La Carta de la Tierra en Acción: Hacia un Mundo Sostenible. Ámsterdam: KIT Publishers BV. Recuperado de: http://www.earthcharterinaction.org/invent/images/uploads/ Westra.pdf

\section{LEGISLACIÓN Y OTROS DOCUMENTOS LEGALES}

Declaración de París sobre Cambio Climático y Generaciones Futuras del 9 de diciembre de 2015. París: III Comisión de Seguridad Regional y Desarrollo Sostenible del Parlamento Andino, Biosfera y Terre des Hommes.

The Papua New Guinea - Mama Graun Tribal Charter: For a Sustainable Future. Carta suscrita por representantes de 870 grupos tribales de Papúa-Nueva Guinea en el año 2002. Recuperada de: http://earthcharter.org/invent/images/uploads/Papua\%20New\%20Guinea\%20 Endorsement.pdf

Declaración de la Conferencia de las Naciones Unidas respecto del Ambiente Humano o Declaración de Estocolmo. Suscrita en dicha ciudad el 16 de junio de 1972 en la Vigésimo Primera Reunión plenaria.

Convenio sobre la prevención de la contaminación del mar por vertimiento de desechos y otras materias o Convenio de Londres. Suscrito en 1972 y entró en vigor en 1975.

Protocolo del Convenio sobre la prevención de la contaminación del mar por vertimiento de desechos y otras materias o Protocolo de Londres. Suscrito en 1996

Convenio sobre la prevención de la contaminación del mar por vertimiento de desechos y otras materias. Suscrito el 13 de noviembre de 1972, entrando en vigor el 30 de agosto de 1975.

Protocolo del Convenio sobre la prevención de la contaminación del mar por vertimiento de desechos y otras materias. Suscrito el 7 de noviembre de 1996, entrando en vigor el 24 de marzo de 2006.

Convención sobre el Comercio Internacional de Especies Amenazadas de Fauna y Flora Silvestres. Suscrita en Washington el 3 de marzo de 1973. Se suscribieron sus Enmiendas en la ciudad de Bonn el 22 de junio de 1979 y, nuevamente, en Gaborone, el 30 de abril de 1983.

Convenio de Barcelona para la protección del Mar Mediterráneo. Suscrita el 16 de febrero de 1976, entrando en vigor el 12 de febrero de 1978. Ha sufrido enmiendas el 9 de julio de 2004. 